\title{
Bioprocessing of Agro-Residual Wastes for Optimisation of Xylanase Production by Aspergillus brasiliensis in Shake Flask Culture and Its Scaling up Elucidation in Stirred Tank Bioreactor
}

\author{
Hooi Ling Ho* and Jee Hsiung Phang \\ Faculty of Applied Sciences, UCSI University, No, Jalan Menara Gading, UCSI Heights, Cheras, 56000 Kuala Lumpur, Malaysia
}

"Corresponding author: Hooi Ling Ho, Faculty of Applied Sciences, UCSI University, No, Jalan Menara Gading, UCSI Heights, Cheras, 56000 Kuala Lumpur, Malaysia, Tel: +6012 369 9854; Fax: +6039102 2614; E-mail: hohooiling@gmail.com

Received date: Dec 23, 2014, Accepted date: Feb 06, 2015, Publication date: Feb 10, 2015

Copyright: @ $2015 \mathrm{Ho} \mathrm{HL}$ et al. This is an open-access article distributed under the terms of the Creative Commons Attribution License, which permits unrestricted use, distribution, and reproduction in any medium, provided the original author and source are credited.

\begin{abstract}
Objective:Xylanase is a hydrolytic enzyme that breaks down backbone of xylan into xylose sugars. This extracellular enzyme possesses many applications in pulp and paper, food and beverage industries. Malaysia as an agricultural country contributes more than 5 million tons of agricultural wastes per year, thus, it is feasible to utilize agro-residual wastes to produce xylanase.

Methods:In the present study, Aspergillus brasiliensis ATCC 16404 was investigated for the production of xylanase in shake flask culture using different agro-residual wastes including wheat bran, sawdust, rice bran, sugarcane bagasse, barley husks, soybean hulls and palm kernel cake. A. brasiliensis was cultured at initial pH 6.5, agitation speed of $150 \mathrm{rpm}$ at $30^{\circ} \mathrm{C}$ for $144 \mathrm{~h}$. Thereafter, the optimised carbon sources obtained from earlier experiments were further elucidated in stirred tank bioreactor. This scaling up study was conducted using $1 \mathrm{~L}$ culture medium at initial $\mathrm{pH} 6.5$, agitation speed of $200 \mathrm{rpm}$ and aeration rate of $1 \mathrm{vvm}$.
\end{abstract}

Results: Based on our results, the highest xylanase activity of $11.2128 \pm 1.7030 \mathrm{U} / \mathrm{mL}$ at $72 \mathrm{~h}$ was observed using pure substrate of xylan in shake flask culture. Agro-residual wastes of wheat bran and sawdust possessed appreciable xylanase activity of $1.1162 \pm 0.0034$ and $1.2343 \pm 0.0809 \mathrm{U} / \mathrm{mL}$ in small scale of submerged fermentation [SmF], respectively. In order to replace the expensive xylan as the prime carbon source, wheat bran and sawdust were thus elucidated as the alternative carbon source in the scale up production of xylanase using stirred tank bioreactor system. Based on the result findings, $A$. brasiliensis yielded relatively higher and faster xylanase production of $3.1126 \pm 0.2462 \mathrm{U} / \mathrm{mL}$ at $72 \mathrm{~h}$ using wheat bran compared to $1.1668 \pm 0.0270 \mathrm{U} / \mathrm{mL}$ from sawdust at $96 \mathrm{~h}$ in bioreactor.

Conclusion:Hence, our study showed that wheat bran was the optimum cost effective substrate for the production of xylanase by $A$. brasiliensis in shorter fermentation period using large scale SmF in stirred tank bioreactor.

Keywords: Xylanase production; Agro-residual wastes; Carbon source; Shake flask culture; Stirred tank bioreactor; Submerged fermentation $[\mathrm{SmF}]$

\section{Introduction}

Lignocellulose, the major reservoir of fixed carbon source in nature, is mainly composed of cellulose, hemicellulose and lignin [1]. It is a major source of organic matter in the forest and used in many industries to produce economical valued products. Nevertheless, the lignocellulosic wastes from agriculture residues are generated in large amounts globally [2]. These agricultural wastes are mostly sold as cattle feed or composted, burned and disposed into landfill which could lead to adverse environmental impacts [3]. Malaysia is an agricultural country which is rich in its natural resources, contributed to more than 5 million tons of wastes per year [4]. Malaysia also spent a lot of money in research on various types of enzymes since no attempts are made to produce the enzymes commercially using local resources [5]. Agricultural residues which are found abundantly in Malaysia such as rice straw, palm kernel cake and sugarcane bagasse could be potentially used as substrates in fermentation to produce enzymes and other value added products [4]. In many industrial processes, enzymes provide a viable alternative to chemical hydrolysis due to its high specificity, besides being environmental friendly [6]. Among all enzymes, hydrolytic xylanase has grown remarkably and aroused a great interest in the past decades $[7,8]$. Xylanase is the extracellular enzyme that hydrolysed xylan. Xylan is majorly consisted of the major component of hemicellulose which is made up of $\beta-, 4$ xylopyranosyl residues linked by glycosidic bonds [8]. From a commercial point of view, xylanase constitutes the major commercial proportion of hemicellulases and thus, has a worldwide market of around 200 million each year [9]. Currently, the major current application of xylanase is bio-bleaching of kraft pulps in pulp and paper industry $[8,10]$. Besides, xylanase is commonly engaged in other major industrial applications such as improving elasticity of dough in baking industry [10], clarification of fruit juices in food and beverage industry and reducing viscosity of animal feed [11]. Other less documented applications of xylanase involved in the production of pharmacologically active polysaccharide for use as antimicrobial agents [12] and the bioconversion of lignocellulosic materials to form 
Citation: Ling Ho H, Phang JH (2015) Bioprocessing of Agro-Residual Wastes for Optimisation of Xylanase Production by Aspergillus brasiliensis in Shake Flask Culture and Its Scaling up Elucidation in Stirred Tank Bioreactor. J Biodivers Biopros Dev 2: 148. doi: $10.4172 / 2376-0214.1000148$

Page 2 of 14

biofuels [13]. To achieve commercial feasibility, enzyme production must increase by introducing a more potent strain. Xylanase is produced by numerous microorganisms, among which the fungi are the most potent producers [14]. However, among all the fungi, filamentous $A$. brasiliensis has received a greater attention for industrial production of xylanase in fermentation [15]. Currently, $80-90 \%$ of commercial xylanases are produced in submerged fermentation $[\mathrm{SmF}]$ because it has a better level of automation and a higher degree of intensification $[10,16]$.

Commercial enzymes are produced in many advanced countries such as Europe, USA and Japan [17]. In view of rising prices of commercial enzymes due to increasing industrial demands, the need for alternative sources of producing enzymes are increasing rapidly in recent years. It is well known that $30-40 \%$ of the production cost of industrial enzymes is taken up by the cost of growth medium [18]. Hence, many studies have been carried out to utilize plant extracts as an approach to reduce the cost of xylanase production. Medium formulation is one of the crucial parameters in fungal growth that has major influences in the production of xylanase. The most important factors of influencing the efficiency of agro-residual wastes are the quality and quantity of carbon source, supplemented with suitable nitrogen source and mineral salts. The production of xylanase by $A$. brasiliensis using $\mathrm{SmF}$ on various carbon sources has been reported in many studies. However, the variation in different xylanase activity would possibly due to different carbon sources used for optimizing the medium formulation. An ideal lignocellulosic substrate should be cheap, easily processed with a high yield and is suitable for the optimum production of enzymes [19]. Therefore, it is feasible for developing countries such as Malaysia, to utilize agro-residual wastes to produce enzymes economically, as well as to lessen the negative impact of agro-residual wastes in the environment. Thus, the objectives of this study was to explore the possibility of utilizing agrowastes effectively to produce xylanase in $\mathrm{SmF}$, to elucidate and determine the optimum agro-residual waste as the cost effective fermentation medium for the production of xylanase by $A$. brasiliensis in SmF using stirred tank bioreactor.

\section{Materials and Methods}

\section{Inoculum development of $\boldsymbol{A}$. brasiliensis ATCC 16404}

A. brasiliensis ATCC 16404 was subcultured on PDA and incubated at $30^{\circ} \mathrm{C}$. The conidia of $A$. brasiliensis on PDA were harvested using an inoculation loop. The spore suspension was then transferred into a falcon tube and proper serial dilutions were prepared. The final spore suspension was adjusted to obtain a concentration of $2 \times 10^{8}$ spores before used as the standard inoculum for every experiment in the shake flask culture. The number of spores was counted using haemocytometer. All of the experiments were conducted twice and the mean value was generated from the analysis.

\section{Pre-treatment of agro-residual wastes as carbon source}

In order to determine the optimum carbon source for the maximum xylanase production by $A$. brasiliensis under SmF, total of seven different agro-residual wastes including wheat bran, sugarcane bagasse, palm kernel cake, rice bran, barley husks, sawdust and soybean hulls were elucidated in this study as the optimised carbon source for xylanase production, respectively. To pre-treat the agroresidual wastes, they were dried in an oven at $80^{\circ} \mathrm{C}$ for $2 \mathrm{~h}$ to obtain the constant moisture content. Then, the dried samples were milled using a miller to produce the fine powder before sieved to obtain the substrates with consistency in particle size.

\section{Preparation of culture medium for xylanase production by $A$. brasiliensis in shake flask culture using different agro- residual wastes as carbon source}

The composition of culture medium for xylanase production by $A$. brasiliensis in shake flask culture was consisted of $[\mathrm{g} / \mathrm{L}]$ : carbon source, 10; yeast extract, 2; $\mathrm{KH}_{2} \mathrm{PO}, 1.52 ; \mathrm{MgSO}_{4} .7 \mathrm{H}_{2} \mathrm{O}, 0.52$ and $\mathrm{KCl}$, $0.52 .1 \mathrm{~g}$ of agro-residual waste was used as the sole carbon source for the preparation of $100 \mathrm{~mL}$ culture medium as the working volume in $250 \mathrm{~mL}$ Erlenmeyer flask in this study. Xylan and glucose used as the carbon source were also elucidated as control in this study, respectively. The initial $\mathrm{pH}$ medium was adjusted to 6.5 before autoclaved. Carbon source and yeast extract with other medium compositions were autoclaved separately at $121^{\circ} \mathrm{C}$ for $15 \mathrm{~min}$ to prevent Millard reaction. Then, the culture medium was inoculated with the standard inoculum size of $2 \times 10^{8}$ spores of $A$. brasiliensis. After inoculation, the culture flask of $\mathrm{SmF}$ was carried out using the optimum growth conditions at $30^{\circ} \mathrm{C}$ at $150 \mathrm{rpm}$ for $144 \mathrm{~h}$. The rest of the experiments were repeated in the similar parameters except for replacing the carbon source with other agro-residual wastes in order to elucidate the optimised carbon source for the maximum xylanase production by $A$. brasiliensis in SmF in shake flask culture before scaling up to stirred tank bioreactor. The optimised carbon source of agro-residual waste would then be used as the first seed culture for the scale up production of xylanase by $A$. brasiliensis in bioreactor.

\section{Preparation of culture medium for xylanase production by $A$. brasiliensis in stirred tank bioreactor using optimised agro-residual wastes as carbon source}

In order to elucidate the scale up production of xylanase in stirred tank bioreactor, $1 \mathrm{~L}$ of culture medium containing the optimised agroresidual waste as the optimum carbon source that determined from the previous experiment was used in $2.5 \mathrm{~L}$ bioreactor. The composition of culture medium for xylanase production by $A$. brasiliensis in stirred tank bioreactor was consisted of $[\mathrm{g} / \mathrm{L}]$ : carbon source, 20; yeast extract, $4 ; \mathrm{KH}_{2} \mathrm{PO}, 1.52 ; \mathrm{MgSO}_{4} .7 \mathrm{H}_{2} \mathrm{O}, 0.52 ; \mathrm{KCl}$, $0.52 ; \mathrm{MnSO}_{4} .4 \mathrm{H}_{2} \mathrm{O}, 0.50 ; \mathrm{CuSO}_{4} .5 \mathrm{H}_{2} \mathrm{O}, 0.50$ and $\mathrm{FeSO}_{4} .7 \mathrm{H}_{2} \mathrm{O}, 0.01$. Total of $100 \mathrm{~mL}$ culture medium containing the optimised carbon source as the first seed culture was inoculated with the standard inoculum size of $2 \times 10^{8}$ spores of $A$. brasiliensis. When the microorganism achieved the logarithmic phase, the culture medium was inoculated into the stirred tank bioreactor to initiate the production of xylanase at $30^{\circ} \mathrm{C}$ at $200 \mathrm{rpm}$ at the aeration rate of $1 \mathrm{vvm}$ for $168 \mathrm{~h}$.

\section{Sampling and analysis}

All of the samples were collected at a regular interval of $24 \mathrm{~h}$ for analysis. Samples were centrifuged at 10,000 rpm for 15 minutes. The clear supernatant was collected and subjected to enzyme activity and protein assays. The determination of biomass concentration of $A$. brasiliensis using dry cell weight was performed using samples directly withdrawn from the experiments. 
Citation: Ling Ho H, Phang JH (2015) Bioprocessing of Agro-Residual Wastes for Optimisation of Xylanase Production by Aspergillus brasiliensis in Shake Flask Culture and Its Scaling up Elucidation in Stirred Tank Bioreactor. J Biodivers Biopros Dev 2: 148. doi: $10.4172 / 2376-0214.1000148$

Page 3 of 14

\section{Xylanase activity assay}

Xylanase activity was determined using method adopted from Bailey et al. [20] with slight modification. Xylan from Beechwood was used as the substrate for the xylanase activity. $0.1 \mathrm{~mL}$ of enzyme supernatant was added together with $0.9 \mathrm{~mL}$ of $1 \%$ xylan in $0.05 \mathrm{M}$ PBS buffer, $\mathrm{pH}$ 5.3. The test tubes were incubated at $50^{\circ} \mathrm{C}$ for $30 \mathrm{~min}$. After $30 \mathrm{~min}, 1.5 \mathrm{~mL}$ of 3,5-dinitrosalicyclic acid [DNS] reagent was added to the mixture and incubated at $90^{\circ} \mathrm{C}$ for $5 \mathrm{~min} .0 .5 \mathrm{~mL} 40 \%$ potassium sodium tartrate was then added to the mixture and left to cool down at room temperature. The absorbance was read at $575 \mathrm{~nm}$ using spectrophotometer. Xylanase activity was expressed as the amount of enzyme required to release $1 \mu \mathrm{mol}$ of xylose per $\mathrm{mL}$ of enzyme extract per minute under assay condition. Xylanase activity was determined according to the xylose standard curve.

\section{Protein assay}

Soluble protein produced by $A$. brasiliensis during xylanase synthesis was determined according to Lowry et al. [21] using Bovine Serum Albumin [BSA] as the standard. The absorbance reading of samples was measured using a spectrophotometer at $750 \mathrm{~nm}$.

\section{Quantification of biomass concentration: dry cell weight}

$1 \mathrm{~mL}$ of sample was withdrawn and filtered onto Whatman no. 1 filter paper. The biomass was dried at $80^{\circ} \mathrm{C}$ until constant weight achieved.

\section{Measurement of $\mathrm{pH}$ medium}

The $\mathrm{pH}$ medium of sample was measured using $\mathrm{pH}$ meter. The $\mathrm{pH}$ meter was calibrated with buffer $\mathrm{pH} 7$ and 10 before use.

\section{Results and Discussion}

\section{Xylanase production by $\boldsymbol{A}$. brasiliensis using different agro- residual wastes as the optimum carbon source in shake flask culture and stirred tank bioreactor}

The aim of the present study is to elucidate and determine the optimum agro-residual waste as the cost effective fermentation medium for the production of xylanase by $A$. brasiliensis. This study was carried out in SmF over fermentation period of $144 \mathrm{~h}$. After determining the optimum carbon source from agro-residual waste on xylanase production in shake flask culture, subsequently, scaling up in SmF was carried out using bioreactor. The objective of scaling up was to determine the production of the xylanase activity by $A$. brasiliensis in large scale fermentation process using alternative cheap sustainable carbon source to reduce the cost of production. Notably, the result findings including xylanase activity, protein concentration, biomass concentration and $\mathrm{pH}$ medium were also investigated in scale up study. In the shake flask culture, $A$. brasiliensis was cultured in medium containing $1 \%[\mathrm{w} / \mathrm{v}]$ carbon concentration and the optimum growth conditions including temperature at $30^{\circ} \mathrm{C}$, initial $\mathrm{pH}$ medium 6.5 and agitation speed of $150 \mathrm{rpm}$ were employed in the study. Among the different Aspergillus species used in xylanase biosynthesis, $A$. brasiliensis has received a great attention to be used in industrial production of xylanase [22,23]. A. brasiliensis remains the best choice to produce xylanase industrially since they excrete xylan degrading enzyme extracellularly into the medium. In addition, filamentous fungi are non-pathogenic in nature and could be easily cultivated [24].
According to Polizeli et al. [10], fungal xylanase levels are found to be higher than other microbial sources. Production of xylanase is inducible as well as constitutive by nature [25]. Medium components such as L-sorbose and xylo-oligosaccharides are responsible for the inducible production of xylanase, whereas enhanced production is obtained only in the medium containing pure xylan and xylan-rich substrates [26]. To date, more than $80-90 \%$ of xylanases are produced in $\mathrm{SmF}$ [10]. Various carbon sources have been used to produce xylanases via SmF. They are mainly wheat bran, rice bran, sugarcane bagasse, rice husks, and wood pulp [27,28]. Therefore, in this study, a variety of carbon sources such as xylan, glucose, wheat bran, sawdust, rice bran, barley husks, soybean hulls, sugarcane bagasse and palm kernel cake were examined for xylanase activity as presented in Figure 1 .

Based on our results, it is obvious that $A$. brasiliensis produced the highest xylanase activity from medium containing xylan in shake flask culture. Initially, the fungus synthesized $3.0789 \pm 0.7116 \mathrm{U} / \mathrm{mL}$ of xylanase from pure substrate of xylan at the beginning of study. Thereafter, at $72 \mathrm{~h}$ of SmF, the fungus utilised most of the nutrients as energy source by secreting the maximum xylanase activity of $11.2128 \pm$ $1.7030 \mathrm{U} / \mathrm{mL}$ by $264.18 \%$ increment. In fact, the production of xylanase by several fungal strains in $\mathrm{SmF}$ was also investigated by Abdel-Naby and Kown [29]. Among all the fungal strains, A. niger NRC 107 appeared to be the best xylanase producer, yielding 8.24 $\mathrm{U} / \mathrm{mL}$ with $1 \%$ xylan used as carbon source in their study. Similar results were also reported. Aspergillus oryzae NRC 13 and Trichorderma viride 250 were also produced appreciable xylanase activity of 4.64 and $2.57 \mathrm{U} / \mathrm{mL}$, respectively. In another study, Chidi et al. [30] produced xylanase activity of $35 \mathrm{U} / \mathrm{mL}$ by Aspergillus terreus UL4209 after $96 \mathrm{~h}$ in YMP supplemented with $1 \%$ oat spelt xylan. It is about 4 times of the maximum activity reported by Abdel-Naby and Kown [29]. Higher yield of xylanase activity always observed in medium containing xylan was probably due to the inducible nature of the enzyme [25]. Besides cellulose, xylan is the most abundant renewable cellulosic polysaccharide present on earth. Xylan is the principle type of hemicellulose found in plant cell wall which comprised of $\beta-, 4$-xylopyranosyl residues [31]. Generally, xylan binds to cellulose strongly by hydrogen bonds and van der walls forces. The composition and structure of xylans found in cell walls could be vary greatly depending on their origin of source. Due to its complex structure, the complete hydrolysis requires the action of several enzymes. The main enzymes involved in the degradation of xylan are consisted of endo- $\beta$-,4-xylanase and $\beta$-,4-xylosidases. Endoxylanase cleaves the xylan backbone into oligosaccharides, which are further hydrolyzed into xylose by xylosidases. The remaining side groups in xylan are liberated by $\alpha$-L-arabinofuranosidase, $\alpha$-D-glucuronidase, ferulic acid esterases and acetyl xylan esterase. It was suggested that the growth of $A$. brasiliensis in xylan enriched medium might have exerted the maximum xylanase secretion, thus promoting and encouraging xylanase biosynthesis. Initially, high molecular weight of xylan could not enter the cells directly and it therefore was not able to induce the synthesis of xylanolytic enzymes. It was reported that low molecular mass fragments of xylan such as xylose, xylobiose and xylooligosaccharides were known to play an important role in xylanase synthesis [32]. Indeed, Thomson [33] proposed that these small soluble fragments were released by the initial action of lower amount of constitutively secreted xylanase which gradually degraded and hydrolysed xylan to generate xylo-oligosaccharides and xylobiose. Subsequently, these simpler compounds were believed to be taken up by the fungus. These compounds were acted as the inducers of 
Citation: Ling Ho H, Phang JH (2015) Bioprocessing of Agro-Residual Wastes for Optimisation of Xylanase Production by Aspergillus brasiliensis in Shake Flask Culture and Its Scaling up Elucidation in Stirred Tank Bioreactor. J Biodivers Biopros Dev 2: 148. doi: $10.4172 / 2376-0214.1000148$

Page 4 of 14

xylanase, subsequently, allowing the complete utilization of xylan [33] Notably, Pang and Omar [34] employed A. niger USM AI1 to obtain the maximum xylanase activity of $25.4 \mathrm{U} / \mathrm{g}$, with the supplementation of xylose at $0.75 \%[\mathrm{w} / \mathrm{w}]$.

In our study, after $72 \mathrm{~h}$ of SmF, the xylanase synthesis by the fungus was depleting due to the diminution of nutrients in the culture medium. Thereafter, lower xylanase activity of $8.4509 \pm 0.1214 \mathrm{U} / \mathrm{mL}$ was observed at $144 \mathrm{~h}$ of SmF. Low xylanase activity by $A$. niger ANL 301 has also been reported by Okafor et al. [35], producing xylanase activity of approximately $0.8 \mathrm{U} / \mathrm{mL}$ at $144 \mathrm{~h}$ using xylan as substrate after achieving the maximum peak at $0.9 \mathrm{U} / \mathrm{mL}$. As a whole, xylan is still considered the best substrate for xylanase production. Nonetheless, it is too expensive as part of the cost production for xylanase. According to the market value, pure substrate of xylan is cost around USD 1,107 per $100 \mathrm{~g}$. In order to produce the highest xylanase activity of $11.2128 \pm 1.7030 \mathrm{U} / \mathrm{mL}, 1 \mathrm{~g}$ of xylan in $100 \mathrm{~mL}$ medium culture which cost USD 11 was needed as part of the cost of production.

Comparatively, it was anticipated to be more expensive than the free charge of agro-residual waste which was sustainably abundant found in the environment. Indeed, lignocellulose, which is the major component of plant biomass, representing the most abundant renewable organic resource in plants, turns out to be as an interesting alternative substrate for the use as the carbon source in industrial scale fermentation. Majority of industrial enzymes are produced by large scale SmF. Hence, agro-industrial wastes could eventually be used as the cheap alternate substrate besides functioned acted as good source of carbon as well as nitrogen.

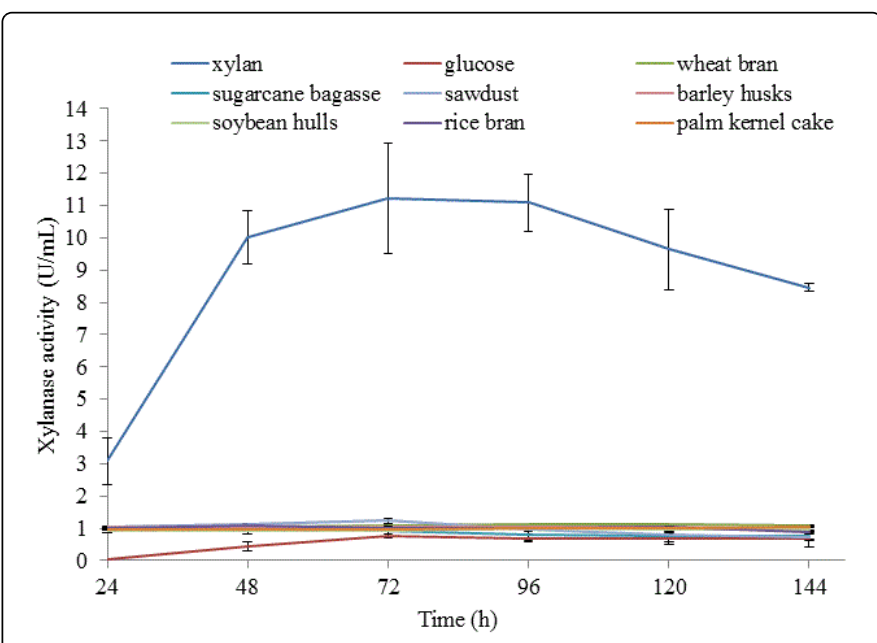

Figure 1: Time course of xylanase production by Aspergillus brasiliensis using different agro-residual wastes compared to xylan and glucose as the sole carbon source in SmF of shake flask culture for $144 \mathrm{~h}$. Xylan and glucose were elucidated as control in this study, respectively.

On the contrary, glucose was found to produce the lowest xylanase activity of $0.7486 \pm 0.0540 \mathrm{U} / \mathrm{mL}$ at $72 \mathrm{~h}$ of $\mathrm{SmF}$ as shown in Figure 1 . After achieving the maximum activity, the enzyme synthesis by the fungus was reduced gradually by $0.11 \%$ to give rise to $0.6690 \pm 0.2428$ $\mathrm{U} / \mathrm{mL}$ at $144 \mathrm{~h}$. In fact, Ronne [36] claimed that most microorganisms would turn off a large number of enzymes encoding genes especially xylanase in the presence of glucose as an energy saving response. Since glucose was a simple sugar that was used efficiently for growth purpose, as a result, $A$. brasiliensis did not require to produce any hydrolytic enzymes in the medium. Therefore, lower xylanase activity was anticipated in the medium containing glucose. Similarly, Kuhad et al. [37] investigated the induction of xylanase production by Fusarium oxysporum NTG-19 in medium containing glucose at $1 \%[\mathrm{w} / \mathrm{v}]$ substrate concentration.

Their result also showed low xylanase activity of $0.6 \mathrm{U} / \mathrm{mL}$ in the medium containing glucose was observed after $120 \mathrm{~h}$ of fermentation. Additionally, pure carbon source of glucose as the defined medium possessed comparatively expensive cost of production on xylanase synthesis, it was hence, the substrate replacement with agro-residual wastes was vastly recommended for scaling up production that would be used in industry.

Likewise, even though xylan is the best carbon source to produce the maximum xylanase biosynthesis, it is not economical for large scale production of xylanase. Since the production cost of industrial enzymes is taken up majorly by the cost of growth medium [18], a better alternative option needed to test and elucidate the cheap agroresidual wastes whether they are suitable for the optimum production of xylanase at $1 \%[\mathrm{w} / \mathrm{v}]$ substrate concentration. The potential of hemicelluloses from agricultural wastes as the renewable raw material is extremely immense. Literally, they are wasted in huge amounts annually.

Nevertheless, it possesses enormous potential if they are found suitably in the application as substrate for xylanase production. Xylanase is one of the most important microbial enzymes that has been categorized as industrially important enzyme [38,39]. The judicious use of xylanases in industries could result in cleaner reactions, lower energy consumption, higher yields and productivity. Overall, xylanase constitutes of major commercial portions of hemicellulases is significantly possessed demand in major enzymes markets all over the years [40]. Hence, the objective of the study was to determine the optimised carbon source using agro-residual waste on xylanase production in SmF using shake flask culture before proceed to elucidation in scaling up study. Based on our results, it shows that A. brasiliensis could produce xylanase when cultured in medium containing different agro-residual wastes in shake flask culture. These inexpensive and easy available agricultural and industrial residues offer as cost effective substrate for the xylanase production as reported by Bakri et al. [41] and Poorma and Prema [42], respectively. Among all agro-residual wastes, interestingly, sawdust appeared to be the alternate optimum option of carbon source to produce xylanase in shake flask culture.

Based on our results, at $72 \mathrm{~h}$ of fermentation, $A$. brasiliensis synthesized the maximum xylanase activity of $1.2343 \pm 0.0809 \mathrm{U} / \mathrm{mL}$ as shown in Figure 2. The xylanase activity then gradually decreased to $0.9780 \pm 0.0742 \mathrm{U} / \mathrm{mL}$ at $96 \mathrm{~h}$, which was probably due to the exhaustion of nutrients in the medium. After $96 \mathrm{~h}$, the xylanase activity gradually reduced further to $0.7318 \pm 0.0776 \mathrm{U} / \mathrm{mL}$ at $144 \mathrm{~h}$. Likewise, according to Okafor et al. [35], in their investigation, they possessed the maximum xylanase activity of $0.68 \mathrm{U} / \mathrm{mL}$ when culturing $A$. niger ANL 301 using sawdust as the energy source. On the other hand, high xylanase activity from sawdust was also reported by Silva et al. [43]. They obtained high xylanase activity of $37 \mathrm{U} / \mathrm{mL}$ by fungal strain Thermoascus aurantiacus Miehe isolated from decayed wood in Brazil. 
Citation: Ling Ho H, Phang JH (2015) Bioprocessing of Agro-Residual Wastes for Optimisation of Xylanase Production by Aspergillus brasiliensis in Shake Flask Culture and Its Scaling up Elucidation in Stirred Tank Bioreactor. J Biodivers Biopros Dev 2: 148. doi: $10.4172 / 2376-0214.1000148$

Page 5 of 14

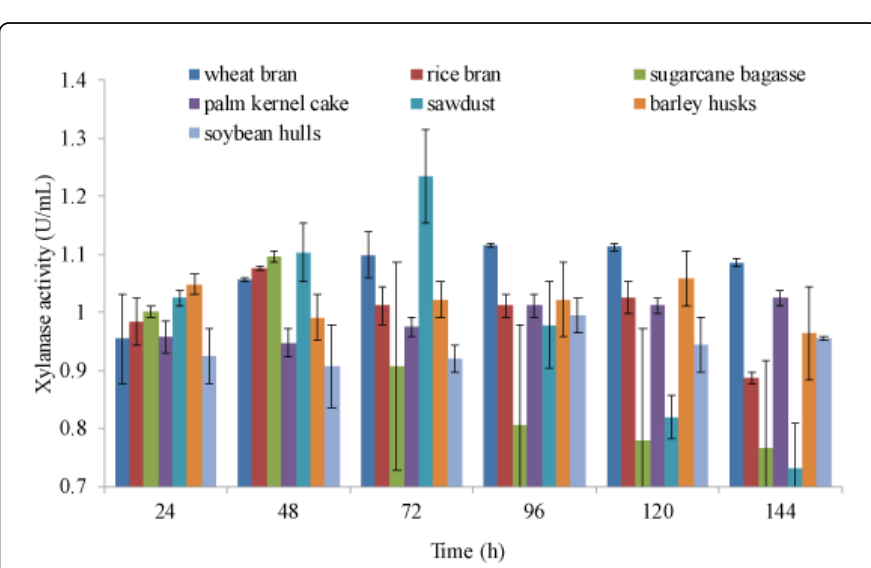

Figure 2: Time course of xylanase production by Aspergillus brasiliensis using different agro-residual wastes as the carbon source in SmF of shake flask culture for $144 \mathrm{~h}$. Wheat bran and sawdust that produced comparable xylanase activity in the small scale of shake flask culture under SmF were scaled up for the enzyme production in bioreactor system.

On the other hand, based on our results, wheat bran also showed identical appreciable xylanase activity as sawdust in shake flask culture. Wheat bran is an inexpensive by-product, which comprised a lot of xylan. Consequently, it became one of the most popular components of complex medium for xylanase production [44]. In Figure 2 , the xylanase activity produced by $A$. brasiliensis using wheat bran increased slowly from $0.9544 \pm 0.0776 \mathrm{U} / \mathrm{mL}$ at $24 \mathrm{~h}$ and reached the highest peak of $1.1162 \pm 0.0034 \mathrm{U} / \mathrm{mL}$ at $96 \mathrm{~h}$, however, with $9.57 \%$ lower xylanase production using sawdust at much earlier $\mathrm{SmF}$ time of $72 \mathrm{~h}$. Studies have showed the production of xylanase on the commercial scale is achieved by using wheat bran as the substrate due to its high xylan content $[8,45]$. The highest level of xylanase activity using wheat bran has been reported by Okafor et al. [35] in A. niger ANL 30, yielding $6.47 \mathrm{U} / \mathrm{mL}$. The xylanase produced by this fungus was approximately 2.5 -fold higher than that by isolated fungi Penicillium oxalicum in the presence of same concentration of wheat bran [46]. Besides, higher yields of xylanase have also been reported by $\mathrm{Pal}$ and Khanum [47]. During the study, A. flavus DFR-6 cultured on wheat bran-supplemented medium was able to produce xylanase activity of $9.2 \mathrm{U} / \mathrm{mL}$. Likewise, Okafor et al. [35] studied the potential of different carbon sources in xylanase production by Penicillium chrysogenum PCL 501 with an initial $\mathrm{pH}$ medium 5.6 at a substrate concentration of $1 \%$. In their study, they also observed the maximum xylanase production in medium containing wheat bran at $96 \mathrm{~h}$ with 6.47 U/mL of activity. In another study, Kuhad et al. [37] also observed the maximum xylanase activity at $96 \mathrm{~h}$ when they cultured hyper xylanolytic fungus Fusarium oxysporum NTG-19 in medium containing wheat bran, producing $18.00 \mathrm{U} / \mathrm{mL}$ of activity. Meanwhile, based on result findings, medium containing sugarcane bagasse and rice bran also synthesized the maximum xylanase activity of $1.0960 \pm$ 0.0101 and $1.0758 \pm 0.0034$ and $\mathrm{U} / \mathrm{mL}$, respectively. Both of their xylanase activity trends were almost identical, in which they possessed the maximum activity peaks at $48 \mathrm{~h}$. On the other hand, medium containing barley husks showed the maximum enzymatic activity peaks of $1.0589 \pm 0.0472 \mathrm{U} / \mathrm{mL}$ at $120 \mathrm{~h}$. Similarly, Ellouze et al. [48] evaluated the time course of xylanase production by Sclerotina sclerotiorum S2 on different carbon sources in SmF. In the study, at
$1 \%$ barley-implemented basal medium, the xylanase activity reached the maximum at $0.83 \mathrm{U} / \mathrm{mL}$ at $240 \mathrm{~h}$. Besides that, xylanase synthesis by $A$. brasiliensis in the medium containing palm kernel cake showed a different trend from other carbon sources. The maximum xylanase activity was found at $144 \mathrm{~h}$ with production of $1.0252 \pm 0.0135 \mathrm{U} / \mathrm{mL}$. Palm kernel cake is the solid residue from the extraction of oil from palm kernel during milling process. It comprised of $57.8 \%$ mannan, $3.7 \%$ xylan and $11.6 \%$ cellulose [49]. Scaling up fermentation of palm kernel cake using glass column bioreactor was reported by Abdeshanian et al. [15]. During the study, A. niger FTCC 5003 produced xylanase activity of $174.88 \mathrm{U} / \mathrm{g}$ at incubation temperature of $25^{\circ} \mathrm{C}$ with the initial moisture level at $60 \%$ and aeration rate at $1.5 \mathrm{~L} /$ min, respectively. On the other hand, in this study, the maximum xylanase activity was also observed in medium containing soybean hulls where it produced $0.9948 \pm 0.0304 \mathrm{U} / \mathrm{mL}$ at $96 \mathrm{~h}$ of fermentation as shown in Figure 2. Soybean hulls contain rich cellulosic composition including $33.49 \%$ cellulose, $17.15 \%$ hemicellulose and $9.88 \%$ lignin [50]. The fungus had a very high affinity towards the soybean hulls, thus, its rich cellulosic composition was appropriate for fungal growth and xylanase production.

A study consisted of the basal liquid medium supplied with different concentrations of rice bran, ranging from 0.25 to $3.0 \%$ was conducted by Kim [51]. This study showed that the production of xylanase by $A$. flavus reached the highest level using $0.5 \%$ rice bran. In another similar study, Gupta et al. [52] studied the effect of substrates and their concentrations by filamentous fungi Fusarium solani F7. Among all the concentrations, 3\% rice bran produced the maximum xylanase by yielding $49 \mathrm{U} / \mathrm{mL}$. Sugarcane bagasse is mainly consisted of fibrous residues of cane stalks obtained after extraction of juice. The sugarcane bagasse residues comprised of approximately $50 \%$ cellulose where $25 \%$ of each is consisted of hemicellulose and lignin, respectively [53]. It is one of the most abundant agro-industrial byproducts that used almost completely as biofuels [53]. The saccharification of such lignocellulosic by-products is an attractive alternative for the management of residual plant biomass, which could be used as substrate for the production of xylanases [54]. Ghoshal et al. [55] performed SsF of various carbon sources by Penicillium citrinum MTCC 2553. It revealed that sugarcane bagasse was the most suitable substrate producing the highest xylanase activity of $1645 \mathrm{U} / \mathrm{g}$ of dried substrate.

Gawande and Kamat [56] compared various lignocelluloses on xylanase production by $A$. niger strain 44 and $A$. terreus strain 5 . They concluded that $A$. niger was more potent in producing xylanase at 24.8 $\mathrm{U} / \mathrm{mL}$ than $A$. terreus at $12.5 \mathrm{U} / \mathrm{mL}$. Likewise, in another study, two local strains of $A$. niger and $T$. viride isolated from fermented rice straw were investigated for xylanase production on various agricultural residues under SsF. When soybean was used as carbon source, $A$. niger was more active in xylanase production yielding $5 \mathrm{U} / \mathrm{g}$ compared to $0.09 \mathrm{U} / \mathrm{g}$ from $T$. viride [57]. Again, A. niger was more active in xylanase production, yielding $12.5 \mathrm{U} / \mathrm{g}$ compared to $11 \mathrm{U} / \mathrm{g}$ from $T$. viride using barley bran as carbon source. As a result, in this study, Aspergillus brasiliensis was selected as it was anticipated to produce sufficient amount of xylanase in SmF of shake flask culture and bioreactor. Table 1 shows the comparison of the maximum xylanase production from sawdust and wheat bran with other agroresidual wastes from shake flask culture in this study. Since both of the sawdust and wheat bran used as carbon source produced comparable maximum xylanase activity in small scale of shake flask culture under $\mathrm{SmF}$, both of them were therefore elucidated for the scale up production of xylanase which maintained at the agitation speed of 200 
Citation: Ling Ho H, Phang JH (2015) Bioprocessing of Agro-Residual Wastes for Optimisation of Xylanase Production by Aspergillus brasiliensis in Shake Flask Culture and Its Scaling up Elucidation in Stirred Tank Bioreactor. J Biodivers Biopros Dev 2: 148. doi: $10.4172 / 2376-0214.1000148$

Page 6 of 14

$\mathrm{rpm}$ and aeration rate of $1 \mathrm{vvm}$ at $30^{\circ} \mathrm{C}$ for $168 \mathrm{~h}$ in a bioreactor system. To begin, the bioreactor study was initiated with $2 \%[\mathrm{w} / \mathrm{v}]$ optimised substrate concentration of sawdust and wheat bran after inoculation of $10 \%[\mathrm{v} / \mathrm{v}]$ inoculum from the first seed culture, respectively.

\begin{tabular}{|l|l|l|}
\hline Agro-residual waste & Time $(\mathbf{h})$ & Maximum xylanase activity $(\mathrm{U} / \mathrm{mL})$ \\
\hline Sawdust & 72 & $1.2343 \pm 0.0809$ \\
\hline Wheat bran & 96 & $1.1162 \pm 0.0034$ \\
\hline Sugarcane bagasse & 48 & $1.0960 \pm 0.0101$ \\
\hline Rice bran & 48 & $1.0758 \pm 0.0034$ \\
\hline Barley with husk & 120 & $1.0589 \pm 0.0472$ \\
\hline Palm kernel cake & 144 & $1.0252 \pm 0.0135$ \\
\hline Soybean hulls & 96 & $0.9948 \pm 0.0304$ \\
\hline
\end{tabular}

Table 1: The maximum xylanase activity produced from sawdust and wheat bran compared to other agro-residual wastes in shake flask culture.

Figure 3 explains the time course production of xylanase by $A$. brasiliensis using wheat bran and sawdust in bioreactor system, respectively. A. brasiliensis produced $2.1380 \pm 0.1147 \mathrm{U} / \mathrm{mL}$ of xylanase from wheat bran at $24 \mathrm{~h}$. As the time of fermentation proceeded, the enzyme synthesis increased gradually up to $45.58 \%$ at $72 \mathrm{~h}$ of SmF, producing $3.1126 \pm 0.2462 \mathrm{U} / \mathrm{mL}$. After $72 \mathrm{~h}$ of SmF, the enzyme activity decreased gradually reaching to $2.3745 \pm 0.1450 \mathrm{U} / \mathrm{mL}$ by $11.06 \%$ at $168 \mathrm{~h}$. The decreased xylanase yield was probably due to the depletion of nutrients from the culture medium, hence causing a negative impact on the fungal growth. Current study in bioreactor shows the huge potential on the production of xylanase whereby approximate increment of 2 -fold was obtained after scaling up using wheat bran as the prime carbon source.

This was anticipated since the bioreactor system offered a better control of aeration and agitation which was able to enhance better growth of the fungus, thus resulting in increase of xylanase production [58]. Moreover, the substrate concentration in bioreactor study was increased to $2 \%[\mathrm{w} / \mathrm{v}]$ that resulted in more nutrients available in the medium, allowing $A$. brasiliensis to use for growth and xylanase synthesis.

The higher substrate concentration in the bioreactor fastened the adaptation of fungus by reducing the lag phase of growth. As a result, it achieved earlier maximum xylanase production at $72 \mathrm{~h}$ where it is a vital concern especially in the industrial point of view. The study on large scale fermentation using wheat bran by $A$. brasiliensis ATCC 16404 was also reported by Velmurugan and Divya [59]. They obtained the maximum xylanase activity of $0.0843 \mathrm{U} / \mathrm{mL}$ from $1 \%$ $[\mathrm{w} / \mathrm{v}]$ wheat bran at $16 \mathrm{~h}$ under optimised conditions with agitation speed of $200 \mathrm{rpm}$ and aeration rate of $1 \mathrm{vvm}$ at $35^{\circ} \mathrm{C}$. Interestingly, the result of xylanase activity in current study was relatively higher compared to the result published by Velmurugan and Divya [59].

This was probably caused by the higher substrate concentration employed in this study, which was sufficient for the fungus to utilize the nutrients for growth as well as to produce xylanase. Most of the studies showed that the substrate concentration is proportional to the production of xylanase.
$\mathrm{Li}$ et al. [60] observed the maximum xylanase activity of 16.11 $\mathrm{U} / \mathrm{mL}$ by Penicillium oxalicum $\mathrm{ZH}-30$ in $10 \mathrm{~L}$ medium containing wheat bran at a concentration of $3.56 \%[\mathrm{w} / \mathrm{v}]$. The fermentation was carried out in 15 - L bioreactor containing $10 \%$ inoculum at $30^{\circ} \mathrm{C}$ with the initial $\mathrm{pH}$ medium of 7.7 , aeration rate of $0.8 \mathrm{vvm}$ and agitation speed at $80 \mathrm{rpm}$.

In another similar study, Bailey and Poutanen [61] carried out fermentation cultivations by $A$. oryzae VTT-D-85248 containing $6 \%$ $[\mathrm{w} / \mathrm{v}]$ of wheat bran in total working volume of $10 \mathrm{~L}$ in stainless steel bioreactor. They produced maximum xylanase activity of $102 \mathrm{U} / \mathrm{mL}$ at optimised conditions with controlled $\mathrm{pH}$ medium from 4.0 to 5.0 at the temperature of $30^{\circ} \mathrm{C}$ with the initial $10 \%$ pre-cultured inoculum.

Therefore, this could explain that by increasing substrate concentration, it would lead to an enhanced enzyme synthesis by $A$. brasiliensis, thus producing higher xylanase activity in medium containing wheat bran as the sole carbon source.

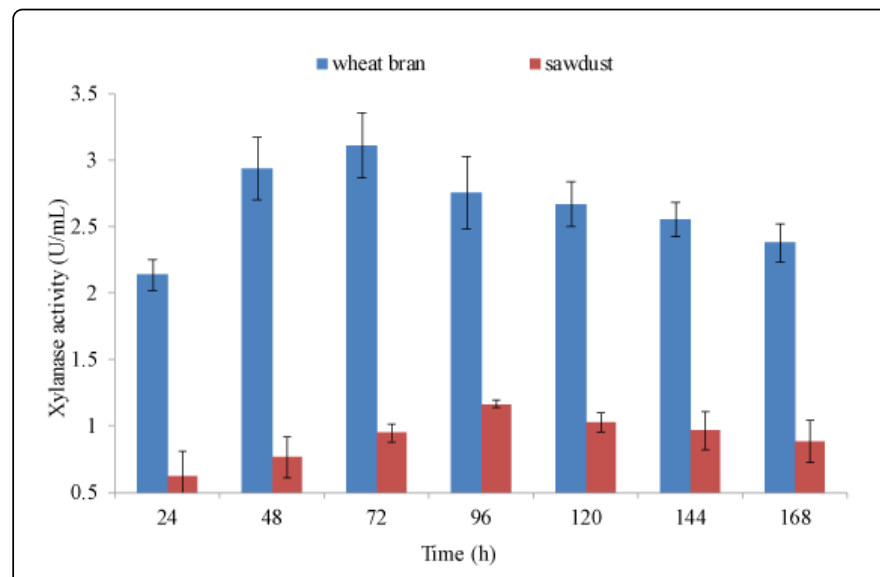

Figure 3: Time course of xylanase production by Aspergillus brasiliensis using agro-residual wastes of wheat bran and sawdust as the carbon source in stirred tank bioreactor for $168 \mathrm{~h}$, respectively. Based on the result, wheat bran was determined as the optimum carbon source, producing $3.1126 \pm 0.2462 \mathrm{U} / \mathrm{mL}$ at $72 \mathrm{~h}$ of $\mathrm{SmF}$ in the bioreactor system.

Besides concentration of substrate influences the production of xylanase, concentration of spores also attributes to the yield and productivity of xylanase. Michelin et al. [62] studied the production of xylanase by $A$. terricola isolated from surface of tree trunks in both stirred tank and airlift bioreactor. In their study, $0.5 \%[\mathrm{w} / \mathrm{v}]$ wheat bran was used as the sole carbon source with direct inoculation of $3 \times$ $10^{8}$ spores into bioreactors.

In the stirred tank bioreactor, at the optimum conditions of $30^{\circ} \mathrm{C}$ with the initial $\mathrm{pH}$ medium 6.0, agitation speed of $300 \mathrm{rpm}$ and aeration of $1 \mathrm{vvm}, 7.45 \mathrm{U} / \mathrm{mL}$ of the maximum xylanase activity was obtained after $36 \mathrm{~h}$ in $1 \mathrm{~L}$ working volume of SmF.

On the other hand, when the fermentation process was carried out in the airlift bioreactor with $6 \mathrm{~L}$ working volume at $30^{\circ} \mathrm{C}$ at initial $\mathrm{pH}$ medium 6.0 with filtered air supplied at 0.07 and $0.17 \mathrm{vvm}$, higher activity than that of observed in the stirred tank bioreactor was observed. At aeration of $0.07 \mathrm{vvm}, 9.27 \mathrm{U} / \mathrm{mL}$ of xylanase activity was observed whereas $12.85 \mathrm{U} / \mathrm{mL}$ of enzyme activity was produced at 0.17 vvm aeration rate. Although the substrate concentration was low, the authors were managed to obtain high yields of xylanase. 
Citation: Ling Ho H, Phang JH (2015) Bioprocessing of Agro-Residual Wastes for Optimisation of Xylanase Production by Aspergillus brasiliensis in Shake Flask Culture and Its Scaling up Elucidation in Stirred Tank Bioreactor. J Biodivers Biopros Dev 2: 148. doi: $10.4172 / 2376-0214.1000148$

Page 7 of 14

This was probably due to higher spore concentration of $3 \times 10^{8}$ spores used in the study. When higher spore concentration was used, wheat bran as carbon source would be utilized at a faster rate, thus producing relatively higher xylanase activity within the shortest fermentation period.

In addition, they also employed the use of optimum stirring speed and aeration rate that would enhance the growth of microorganism, thereby increasing the production of xylanase in bioreactor.

Figure 4 shows the correlation of xylanase activity and biomass concentration of $A$. brasiliensis using wheat bran as the optimised carbon source in bioreactor. The production of xylanase was accompanied with the increase in biomass concentration from $24 \mathrm{~h}$ to achieve its maximum peak of activity at $72 \mathrm{~h}$.

This indicates that hemicelluloses in wheat bran had been hydrolysed to reducing sugar by xylanase to promote the growth of $A$. brasiliensis. Thereafter, the biomass concentration reduced gradually towards the end of fermentation period due to depletion of nutrients including xylose which resulted in decreasing xylanase activity started from $72 \mathrm{~h}$ onward.

In the current study, wheat bran seems to be more susceptible to $A$. brasiliensis in producing higher amounts of xylanase in bioreactor compared to sawdust. This may be due to the fact that wheat bran comprised high percentage composition of $60 \%$ carbohydrates along with $12 \%$ protein, $0.5 \%$ fat and $2 \%$ minerals [63].

In addition, wheat bran has a high xylan content of $18.3 \%$ which is proven to be suitable for the production of xylanase [45]. For commercial applications, xylanase should ideally be produced quickly in large quantities from simple and inexpensive substrates. Pandey [64] stated that wheat bran is one of the most attractive alternatives as the natural substrate in fermentation processes. It is a good substrate as a result of its loose particle binding which allow efficient penetration by mycelia due to its low lignin content [65].

Several reports have also showed that, besides xylan, wheat bran could also be used as an inducer for production of variety of enzymes such as cellulase, amylase, protease, lipase, invertase and phytase [6,66]. Meanwhile, Kulkarni et al. [32] and Subramanyan and Prema [8] claimed that xylanase production in commercial scale using wheat bran as the substrate is feasible since it is an agro-economical inducer due to its high xylan content.

Notably, wheat bran used in bioreactor showed that shorter fermentation period was required to achieve the maximum xylanase production. In fact, this was probably due to the active fungal of the first seed culture that was inoculated into the bioreactor. The fungal culture of the inoculum was prepared by introducing $2 \times 10^{8}$ spores into the medium.

At $72 \mathrm{~h}$ of fermentation, $A$. brasiliensis reached the maximum growth in the bioreactor study. The use of active fungal culture in the bioreactor could reduce the adaptation time of the fungal during the lag phase. The agro-residual waste could therefore, be fully utilised by $A$. brasiliensis to produce the maximal xylanase yield within the shortest fermentation period. On the other hand, in another experiment, xylanase production was also carried out by $A$. brasiliensis using sawdust enriched medium in large scale fermentation of bioreactor. Based on our result findings, sawdust showed lower xylanase activity with prolonged fermentation period. The fungus produced $0.6272 \pm 0.1821 \mathrm{U} / \mathrm{mL}$ of xylanase activity from sawdust at $24 \mathrm{~h}$ of fermentation. The enzyme synthesis was increased gradually with increase of fermentation time up to $96 \mathrm{~h}$ with $1.1668 \pm 0.0270$ $\mathrm{U} / \mathrm{mL}$. A decreasing trend of $11.85 \%$ was observed at $120 \mathrm{~h}$, producing $1.0285 \pm 0.0708 \mathrm{U} / \mathrm{mL}$.

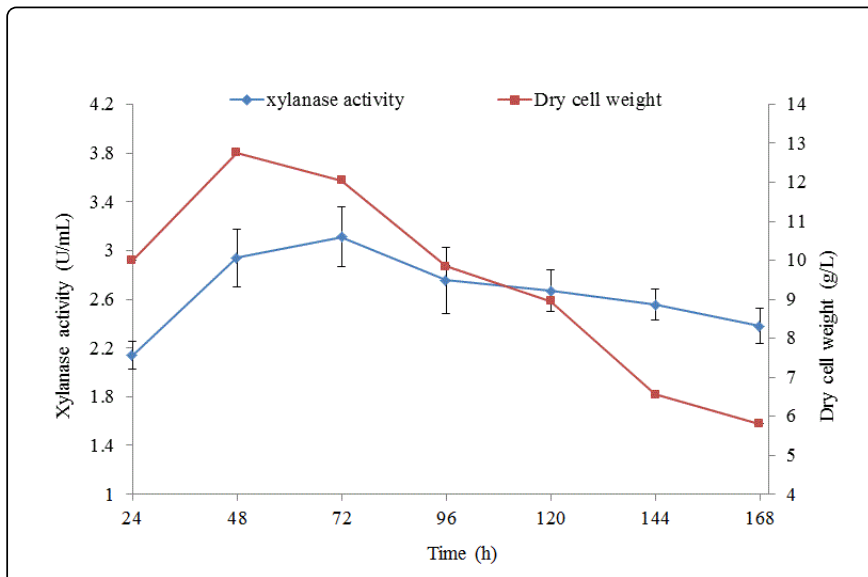

Figure 4: The correlation of xylanase production and biomass concentration of Aspergillus brasiliensis using the optimum agroresidual waste of wheat bran as the sole carbon source in stirred tank bioreactor for $168 \mathrm{~h}$. The production of xylanase was achieved with the increase in biomass concentration from $24 \mathrm{~h}$ to attain its maximum peak of activity at $72 \mathrm{~h}$.

The decrease in enzyme activity observed after the second day of incubation could possibly be due to the accumulation of metabolic waste and production of proteases which might inhibit the xylanase activity [67]. Sawdust is a natural raw material that exhibits a high polarity mainly due to the presence of different oxygen-containing functional groups such as alcohol and ether [68].

The cell wall of sawdust is mainly consisted of cellulose, lignin, tannins or other phenolic compounds. The lignin content of hardwoods is usually in the range of 18 to $25 \%$, whereas that of softwoods varies between 25 to $35 \%$ [69]. The high lignin content in sawdust which was less sensitive and accessible to chemical and enzymatic reaction, might limit the access of the hemicelluloses to hydrolytic enzymes [56]. It thus, resulted in lower xylanase activity produced in the bioreactor. In order to improve the productivity of xylanase yield in the current study, acid or alkaline pretreatment procedures could be applied to improve the susceptibility of hemicelluloses of substrates to xylanase hydrolysis [70]. HahnHagerdal et al. [71] reviewed that alkaline pretreatment was the most suitable method to remove lignin in raw materials, which makes the hemicellulose more accessible to the xylanase. As a result, the hydrolysis of pre-treated residues by $A$. brasiliensis would be faster, thus increasing the enzymatic yield. Table 2 compares the maximum xylanase production from wheat bran and sawdust as the carbon source in bioreactor study.

\begin{tabular}{|l|l|l|}
\hline Agro-residual waste & Time $(\mathrm{h})$ & Maximum xylanase activity $(\mathrm{U} / \mathrm{mL})$ \\
\hline Wheat bran & 72 & $3.1126 \pm 0.2462$ \\
\hline Sawdust & 96 & $1.1668 \pm 0.0270$ \\
\hline
\end{tabular}

Table 2: The maximum xylanase production obtained from wheat bran and sawdust as the carbon source in bioreactor study. 
Citation: Ling Ho H, Phang JH (2015) Bioprocessing of Agro-Residual Wastes for Optimisation of Xylanase Production by Aspergillus brasiliensis in Shake Flask Culture and Its Scaling up Elucidation in Stirred Tank Bioreactor. J Biodivers Biopros Dev 2: 148. doi: $10.4172 / 2376-0214.1000148$

Page 8 of 14

Consequently, based on our result findings, medium containing sawdust without pre-treatment of acid and alkaline as a carbon source gave lower xylanase activity. Ritschkoff et al. [72] also observed the low xylanase activity in medium containing $1 \%$ sawdust after $216 \mathrm{~h}$ when they cultured homogenized Gloeophyllum trabeum BAM Ebw 109 using air-lift bioreactor with $1.2 \mathrm{~L}$ of the working volume. On the other hand, Paice et al. [73] observed lower xylanase activity in medium containing $4 \%$ sawdust. In the study, 3-day old culture which consisted of Schizophyllum commune ATCC 38548 was employed in $10 \mathrm{~L}$ fermentation medium containing $4 \%$ sawdust at optimised conditions of $\mathrm{pH} 3.9$ at $30^{\circ} \mathrm{C}$. Even though higher substrate concentration of $4 \%$ was employed, lower xylanase activity of 0.37 $\mathrm{U} / \mathrm{mL}$ was observed after $216 \mathrm{~h}$.

Based on our results, $A$. brasiliensis produced the maximum xylanase activity of $1.2343 \pm 0.0809$ and $1.1668 \pm 0.0270 \mathrm{U} / \mathrm{mL}$ using sawdust as sole carbon source in shake flask culture and bioreactor, respectively. The increase of the substrate concentration to $2 \%$ did not further enhance the synthesis of enzyme by $A$. brasiliensis, thus the concentration of substrate is suggested to remain at $1 \%$ in large scale fermentation in order to reduce the cost of production.

Cowan [74] reported that the lignocellulosic material contained secondary metabolite compounds such as antimicrobial agents that could inhibit the growth of microorganisms. Therefore, it could be suggested that the growth of $A$. brasiliensis was anticipated to be affected by higher amount of secondary metabolites derived from the fermentation using $2 \%[\mathrm{w} / \mathrm{v}]$ substrate concentration. Consequently, the production of xylanase by $A$. brasiliensis would also be affected. Previously, Sumthong [75] observed that sawdust extract could inhibit the growth of $A$. niger. In fact, the presence of tannin in sawdust could be toxic to filamentous fungus, yeast and bacteria [76,77].

Tannins are generally known to inactivate microbial enzymes and cell envelope transport proteins [78]. Based on our results, bioreactor study showed that wheat bran was a better carbon source for xylanase production compared to sawdust. Wheat bran gave rise to relatively much higher xylanase yield of $165.81 \%$, producing $3.11 \pm 0.25 \mathrm{U} / \mathrm{mL}$ than the sawdust which was $1.17 \pm 0.07 \mathrm{U} / \mathrm{mL}$.

In addition, the period of optimum xylanase activity varied between the two carbon sources. The time of maximum xylanase production was shorter for wheat bran at $72 \mathrm{~h}$ than sawdust at $96 \mathrm{~h}$. The shorter fermentation time offers several advantages such as reduced risk of contamination as well as decreased cost of enzyme production.

Hence, we conclude that wheat bran is the best prospective carbon source for the production of the xylanase in large scale fermentation. Table 3 demonstrates the maximum xylanase activity produced using wheat bran as the optimised carbon source by $A$. brasiliensis in shake flask culture and bioreactor, respectively.

\begin{tabular}{|l|l|l|}
\hline Submerged fermentation & Time $(\mathbf{h})$ & Maximum xylanase activity $(\mathrm{U} / \mathrm{mL})$ \\
\hline Shake flask culture & 96 & $1.1162 \pm 0.0034$ \\
\hline Bioreactor & 72 & $3.1126 \pm 0.2462$ \\
\hline
\end{tabular}

Table 3: The maximum xylanase activity produced using wheat bran as the optimised carbon source by $A$. brasiliensis in shake flask culture and bioreactor.

\section{Biomass production of $\boldsymbol{A}$. brasiliensis using different agro- residual wastes as the optimum carbon source in shake flask culture and bioreactor}

Figure 5 demonstrates the maximum biomass concentration of dry cell weight observed in medium containing rice bran at $72 \mathrm{~h}$ in shake flask culture. Initially, the biomass concentration increased gradually from $2.5350 \pm 1.1350 \mathrm{~g} / \mathrm{L}$ at $24 \mathrm{~h}$ by $132.94 \%$, producing $5.9050 \pm$ $0.5850 \mathrm{~g} / \mathrm{L}$ at $72 \mathrm{~h}$. The highest mycelial growth was found in rice bran because it contained carbohydrate that could be used as the carbon and energy source for the growth of fungus [79]. According to Oshoma and Ikenebomeh [80], they obtained the maximum mycelial weight of $2.03 \pm 0.02 \mathrm{~g} / \mathrm{L}$ in glucose medium supplemented with rice bran. In shake flask culture, medium containing soybean hulls was the optimum carbon source after rice bran, for achieving high mycelial weight at $48 \mathrm{~h}$, giving rise to $5.3500 \pm 0.4500 \mathrm{~g} / \mathrm{L}$.

Brijwani et al. [50] stated that the soybean hulls possessed rich cellulosic composition that was appropriate for fungal growth. Medium containing barley husks also achieved the maximum biomass concentration of $2.9070 \pm 0.2265 \mathrm{~g} / \mathrm{L}$ at $48 \mathrm{~h}$. Other agro-residual substrates such as sugarcane bagasse, wheat bran and sawdust showed no significant differences in mycelial weight, producing $2.0050 \pm$ $0.1280,1.9850 \pm 0.2150$ and $2.1500 \pm 0.1500 \mathrm{~g} / \mathrm{L}$, respectively. However, the lowest biomass concentration of $73.41 \%$ was obtained, showing $1.5700 \pm 0.2200 \mathrm{~g} / \mathrm{L}$ in medium containing palm kernel cake compared to rice bran.

Meanwhile, for medium containing glucose as the sole carbon source in shake flask culture, the biomass concentration increased of $163.97 \%$ from $0.6800 \pm 0.0200 \mathrm{~g} / \mathrm{L}$ at $24 \mathrm{~h}$ to reach the maximum of $1.7950 \pm 0.1350 \mathrm{~g} / \mathrm{L}$ at $72 \mathrm{~h}$. This study was supported by Chinedu et al. [81], where the peak biomass concentration of $A$. niger ANL 301 was found at $72 \mathrm{~h}$, with $1.56 \mathrm{mg} / \mathrm{mL}$. A similar growth rate was observed in the medium containing xylan, where the maximum biomass concentration was obtained at $72 \mathrm{~h}$, producing $1.5910 \pm$ $0.0310 \mathrm{~g} / \mathrm{L}$.

After $72 \mathrm{~h}$, both xylan and glucose showed a sharp decrease of mycelial weight at $96 \mathrm{~h}$, attaining $0.9950 \pm 0.075$ and $0.8850 \pm 0.0850$ $\mathrm{g} / \mathrm{L}$, respectively. This might be due to that both xylan and glucose were more readily assimilated and metabolized by $A$. brasiliensis. Since xylan and glucose possess simpler chemical structure compared to other carbon sources, there is a greater chance for the microorganism to grow rapidly.

At $120 \mathrm{~h}$ of SmF, A. brasiliensis assimilated most of the simple sugars in xylan and glucose-containing medium, hence, resulting in decreasing of growth rate as much as $57.23 \%$ and $59.05 \%$, producing only $0.6805 \pm 0.0305$ and $0.7350 \pm 0.0550 \mathrm{~g} / \mathrm{L}$ of biomass concentration, respectively.

As shown in Figure 5, most of the carbon sources showed different maximum peak of growth in shake flask culture. The biomass concentration was attained at $48 \mathrm{~h}$ for sawdust, barley, and soybean hull whereas another peak biomass concentration was occurred at $72 \mathrm{~h}$ for the medium containing rice bran, glucose or xylan as sole carbon source. On the contrary, palm kernel cake, sugarcane bagasse and wheat bran showed a different trend of growth.

On the other hand, the peak of mycelial weight for medium containing palm kernel cake and sugarcane bagasse was attained at 96 $\mathrm{h}$ while wheat bran showed growth peaks at $120 \mathrm{~h}$. The differences in the carbon sources of the medium could be accounted for the disparity 
Citation: Ling Ho H, Phang JH (2015) Bioprocessing of Agro-Residual Wastes for Optimisation of Xylanase Production by Aspergillus brasiliensis in Shake Flask Culture and Its Scaling up Elucidation in Stirred Tank Bioreactor. J Biodivers Biopros Dev 2: 148. doi: $10.4172 / 2376-0214.1000148$

Page 9 of 14

in the growth of the microorganism in different substrates. Agroresidual substrates are composed of complex plant cell wall components, including cellulose, hemicellulose and lignin [70]. Beginning of the current study shows a gradual increase of dry cell weight in all agro-residual substrates, as a result of slower metabolism of the microorganism.

Therefore, in order to obtain simple sugar for growth, the microorganisms require enzymes to hydrolyze more complex structure of the substrates. Table 4 shows the biomass concentration obtained from different carbon sources in shake flask culture.

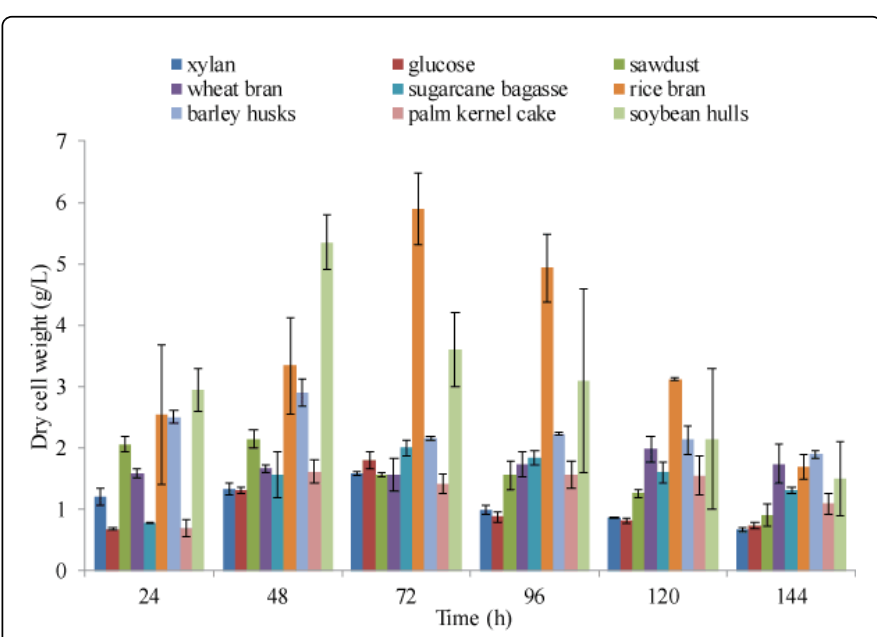

Figure 5: Time course of biomass concentration of Aspergillus brasiliensis using different agro-residual wastes compared to xylan and glucose as the sole carbon source in SmF of shake flask culture for $144 \mathrm{~h}$. Xylan and glucose were elucidated as control in this study, respectively.

Notably, in bioreactor study, wheat bran possess the highest biomass concentration of $12.7500 \pm 0.0006 \mathrm{~g} / \mathrm{L}$ at $48 \mathrm{~h}$ as shown in Figure 6. After $48 \mathrm{~h}$ of SmF, the dry cell weight started to decrease from $12.0500 \pm 0.0013 \mathrm{~g} / \mathrm{L}$ before giving rise to reach $5.8000 \pm 0.0006$ $\mathrm{g} / \mathrm{L}$ at $168 \mathrm{~h}$.

On the contrary, sawdust possess lower biomass concentration by attaining the maximum mycelial weight from 48 to $72 \mathrm{~h}$, giving rise to $10.0000 \pm 0.0001$ and $10.1000 \pm 0.0006 \mathrm{~g} / \mathrm{L}$, respectively. After achieving the maximum growth, the mycelial weight decreased to $7.9500 \pm 0.0007 \mathrm{~g} / \mathrm{L}$ at $72 \mathrm{~h}$ and $5.4000 \pm 0.0007 \mathrm{~g} / \mathrm{L}$ at $168 \mathrm{~h}$, respectively.

\begin{tabular}{|l|l|l|}
\hline Carbon source & Time $(\mathbf{h})$ & Maximum biomass concentration $\mathbf{( g / L )}$ \\
\hline Xylan & 72 & $1.5910 \pm 0.0310$ \\
\hline Glucose & 72 & $1.7950 \pm 0.1350$ \\
\hline Sawdust & 48 & $2.1500 \pm 0.1500$ \\
\hline Wheat bran & 120 & $1.9850 \pm 0.2150$ \\
\hline Sugarcane bagasse & 96 & $2.0050 \pm 0.1280$ \\
\hline Rice bran & 72 & $5.9050 \pm 0.5850$ \\
\hline Barley husk & 48 & $2.9070 \pm 0.2265$ \\
\hline
\end{tabular}

\begin{tabular}{|l|l|l|}
\hline Palm kernel cake & 96 & $1.5700 \pm 0.2200$ \\
\hline Soybean hulls & 48 & $5.3500 \pm 0.4500$ \\
\hline
\end{tabular}

Table 4: The maximum biomass concentration obtained from different carbon sources in shake flask culture.

Notably, based on the present findings in bioreactor, it is suggested that by increasing the wheat bran concentration to $2 \%[\mathrm{w} / \mathrm{v}]$, it would enhance the growth of the fungus, thereafter, increase the yield of xylanase production in the medium.

Additionally, the biomass concentration of bioreactor study was about 6 times higher after scaling up with the fungus, whereby it reached the maximum growth at shorter fermentation period.

Both wheat bran and sawdust showed similar graphical growth pattern in Figure 6, as they achieved the maximum mycelial weight at approximately $48 \mathrm{~h}$. However, wheat bran showed higher biomass concentration than sawdust.

Table 5 shows the maximum biomass concentration produced from wheat bran and sawdust in bioreactor. Kang et al. [82] reported that the growth of fungus was affected by the nature of the substrate used in fermentation. This seems that wheat bran has a higher concentration of nutrients that makes it more suitable for the fungal growth.

On the other hand, as reported by Cowan [74], the lignocellulosic material that contained secondary metabolite compounds with the antimicrobial properties could inhibit the growth of microorganisms.

Therefore, this suggested that the lower biomass concentration was anticipated in medium containing sawdust. Table 6 shows the maximum biomass concentration produced using wheat bran as the optimised carbon source by $A$. brasiliensis in shake flask culture and bioreactor, respectively.

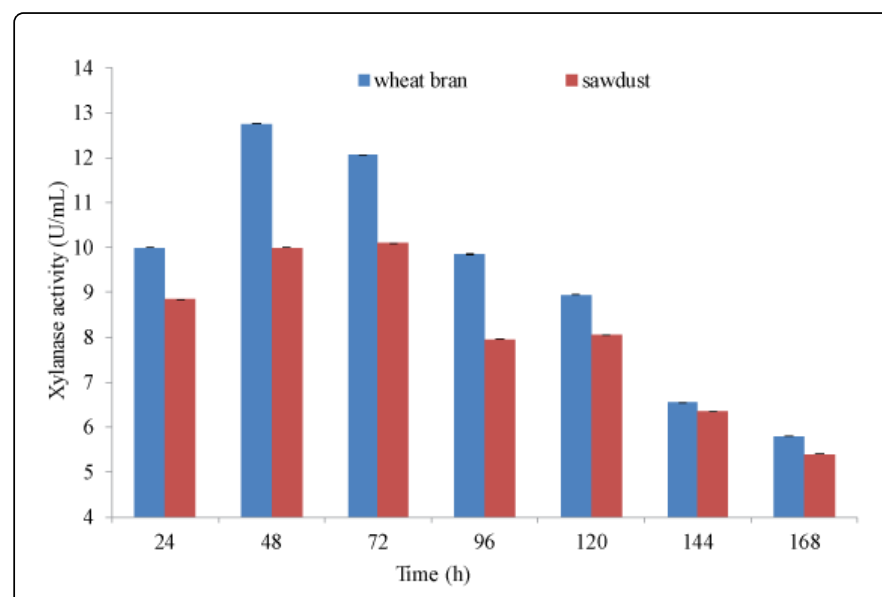

Figure 6: Time course of biomass concentration by Aspergillus brasiliensis using agro-residual wastes of wheat bran and sawdust as the carbon source in stirred tank bioreactor for $168 \mathrm{~h}$, respectively. Based on the result, wheat bran was elucidated as the optimum carbon source, producing $12.7500 \pm 0.0006 \mathrm{~g} / \mathrm{L}$ at $48 \mathrm{~h}$ of $\mathrm{SmF}$ in the bioreactor system. 
Citation: Ling Ho H, Phang JH (2015) Bioprocessing of Agro-Residual Wastes for Optimisation of Xylanase Production by Aspergillus brasiliensis in Shake Flask Culture and Its Scaling up Elucidation in Stirred Tank Bioreactor. J Biodivers Biopros Dev 2: 148. doi: $10.4172 / 2376-0214.1000148$

Page 10 of 14

\begin{tabular}{|l|l|l|}
\hline Agro-residual waste & Time $(\mathbf{h})$ & Maximum biomass concentration(g/L) \\
\hline Wheat bran & 48 & $12.7500 \pm 0.0006$ \\
\hline Sawdust & 72 & $10.1000 \pm 0.0001$ \\
\hline
\end{tabular}

Table 5: The maximum biomass concentration produced from wheat bran and sawdust in bioreactor.

\begin{tabular}{|l|l|l|}
\hline Agro-residual waste & Time $(\mathbf{h})$ & Maximum biomass concentration $(\mathbf{g} / \mathbf{L})$ \\
\hline Shake flask culture & 120 & $1.9850 \pm 0.2150$ \\
\hline Bioreactor & 48 & $12.7500 \pm 0.0006$ \\
\hline
\end{tabular}

Table 6: The maximum biomass concentration produced using wheat bran as the optimised carbon source by $A$. brasiliensis in shake flask culture and bioreactor.

\section{Soluble protein production of $A$. brasiliensis using different agro-residual wastes as the optimum carbon source in shake flask culture and bioreactor}

Lowry method was used to determine the concentration of soluble protein produced by $A$. brasiliensis during xylanase synthesis. The protein released by $A$. brasiliensis in the medium containing the respective carbon sources from shake flask culture is shown in Figure 7. Cultures containing wheat bran and rice bran gave rise to higher protein concentration compared to other carbon sources. Wheat bran exhibited the highest protein concentration of $7.6057 \pm 0.0589 \mathrm{mg} / \mathrm{mL}$ followed by rice bran of $7.5017 \pm 1.7013 \mathrm{mg} / \mathrm{mL}$.

Fungus such as Aspergillus spp is known to produce many hydrolyzing enzymes [83]. Therefore, the higher protein yield from wheat bran suggested the presence of xylanase as well as other proteins. Previously, Gawande and Kamat [56] observed higher extracellular protein of 1.8 and $1.9 \mathrm{mg} / \mathrm{mL}$ from wheat bran compared to other agro-residual wastes when they cultured $A$. terreus strain 5 and $A$. niger strain 4, respectively.

Other carbon sources such as soybean hulls, xylan, palm kernel cake, glucose and sugarcane bagasse exhibited protein concentration of $6.0638 \pm 0.2356,5.7311 \pm 0.090,5.1040 \pm 0.3016,4.6050 \pm 0.7658$ and $4.3174 \pm 0.3326 \mathrm{mg} / \mathrm{mL}$, respectively. The lowest protein concentration was obtained from barley husk with $4.3035 \pm 0.2911$ $\mathrm{mg} / \mathrm{mL}$. Table 7 shows the maximum soluble protein produced by $A$. brasiliensis using different carbon sources in shake flask culture.

Figure 8 from the bioreactor study shows the protein released by $A$. brasiliensis using wheat bran and sawdust, respectively. Initially, the fungus was survived at the adaptation stage, whereby it could not synthesis necessary proteins in the medium. After 24 of fermentation in bioreactor, $A$. brasiliensis started to synthesize the maximum soluble proteins from the medium containing wheat bran and sawdust, respectively.

The production of soluble protein from both wheat bran and sawdust by $A$. brasiliensis remained almost stationary until the end of fermentation period. In terms of protein yield, higher soluble protein concentration was obtained in medium containing wheat bran comparing to that containing sawdust.
From Table $8, A$. brasiliensis possessed the maximum protein yield using wheat bran and sawdust, producing $12.6126 \pm 1.3860$ and $12.4567 \pm 0.0035 \mathrm{mg} / \mathrm{mL}$, respectively.

Both carbon sources showed higher protein levels in bioreactor than others obtained in small scale fermentation. This was probably due to the increase of substrate concentration tends to favor the growth of the microorganisms, therefore producing higher amounts of proteins in the medium. As shown in Table 8 and 9, the protein concentration obtained in bioreactor increased about two-fold after scaling up.

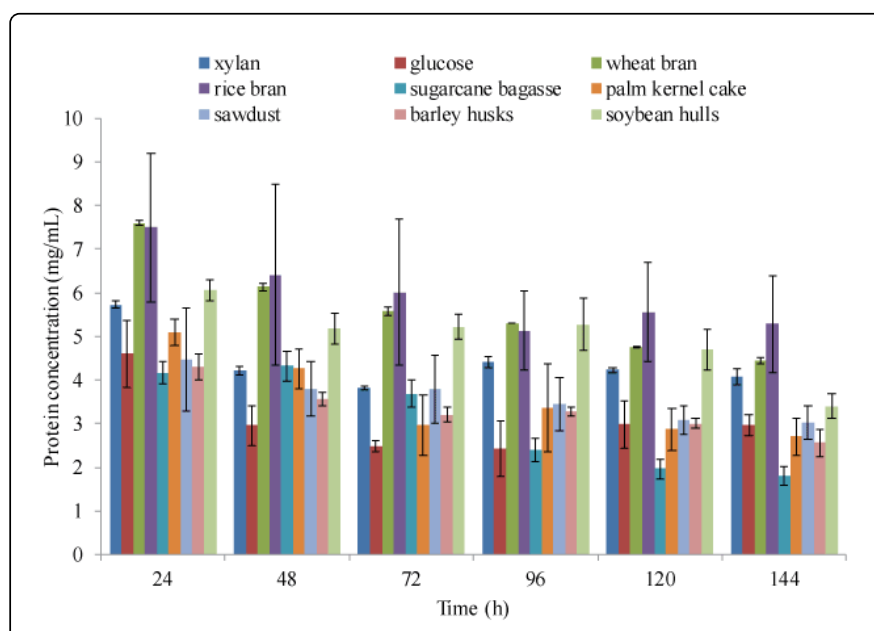

Figure 7: Time course of protein concentration of Aspergillus brasiliensis using different agro-residual wastes compared to xylan and glucose as the sole carbon source in SmF of shake flask culture for $144 \mathrm{~h}$. Xylan and glucose were elucidated as control in this study, respectively.

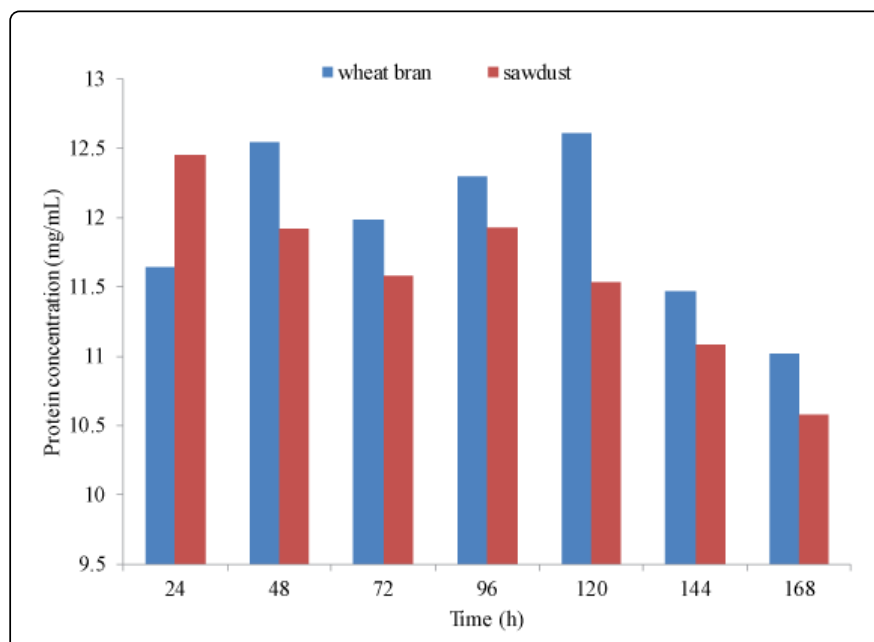

Figure 8: Time course of protein concentration by Aspergillus brasiliensis using agro-residual wastes of wheat bran and sawdust as the carbon source in stirred tank bioreactor for $168 \mathrm{~h}$, respectively. Based on the result, $A$. brasiliensis produced the maximum protein yield using wheat bran and sawdust, producing $12.6126 \pm 1.3860$ and $12.4567 \pm 0.0035 \mathrm{mg} / \mathrm{mL}$, respectively. 
Citation: Ling Ho H, Phang JH (2015) Bioprocessing of Agro-Residual Wastes for Optimisation of Xylanase Production by Aspergillus brasiliensis in Shake Flask Culture and Its Scaling up Elucidation in Stirred Tank Bioreactor. J Biodivers Biopros Dev 2: 148. doi: $10.4172 / 2376-0214.1000148$

Page 11 of 14

\section{pH medium profile of $\boldsymbol{A}$. brasiliensis during xylanase production using different agro-residual wastes as the optimum carbon source in shake flask culture and bioreactor}

In the study of shake flask culture, the $\mathrm{pH}$ medium profile of all agro-residual wastes as carbon source fall in the range from $\mathrm{pH} 5$ to 7 as shown in Figure 9.

Table 10 shows the optimum $\mathrm{pH}$ medium for the production of xylanase from different carbon sources in shake flask culture. Xylan that produced the highest xylanase activity of $11.2128 \pm 1.7030 \mathrm{U} / \mathrm{mL}$ occurred when the $\mathrm{pH}$ medium decreased from $6.5200 \pm 0.0100$ to $6.1900 \pm 0.0200$.

\begin{tabular}{|l|l|}
\hline Carbon source & Protein concentration $(\mathrm{mg} / \mathrm{mL})$ \\
\hline Xylan & $5.7311 \pm 0.0901$ \\
\hline Glucose & $4.6050 \pm 0.7658$ \\
\hline Sawdust & $4.4768 \pm 1.1781$ \\
\hline Wheat bran & $7.6059 \pm 0.0589$ \\
\hline Sugarcane bagasse & $4.3174 \pm 0.3326$ \\
\hline Rice bran & $7.5017 \pm 1.7013$ \\
\hline Barley with husk & $4.3035 \pm 0.2911$ \\
\hline Palm kernel cake & $5.1040 \pm 0.3016$ \\
\hline Soybean hulls & $6.0637 \pm 0.2356$ \\
\hline
\end{tabular}

Table 7: The maximum soluble protein concentration obtained from different carbon sources in shake flask culture.

\begin{tabular}{|l|l|l|}
\hline Agro-residual waste & Time $(\mathrm{h})$ & $\begin{array}{l}\text { Maximum protein concentration } \\
(\mathbf{m g} / \mathbf{m L})\end{array}$ \\
\hline Wheat bran & 120 & $12.6126 \pm 1.3860$ \\
\hline Sawdust & 24 & $12.4567 \pm 0.0035$ \\
\hline
\end{tabular}

Table 8: The maximum soluble protein concentration obtained from wheat bran and sawdust in bioreactor.

\begin{tabular}{|l|l|l|}
\hline $\begin{array}{l}\text { Agro-residual } \\
\text { waste }\end{array}$ & Time (h) & Maximum protein concentration $(\mathrm{mg} / \mathrm{mL})$ \\
\hline Shake flask culture & 24 & $7.6057 \pm 0.0589$ \\
\hline Bioreactor & 120 & $12.6126 \pm 1.3860$ \\
\hline
\end{tabular}

Table 9: The maximum protein concentration produced using wheat bran as the optimised carbon source by $A$. brasiliensis in shake flask culture and bioreactor.

It was found that at slightly acidic condition, it would favor enzyme synthesis of xylanase by $A$. brasiliensis, thus resulting in obtaining the maximum xylanase yield. Similar findings were also reported for xylanase production by $A$. terreus UL 4209 . Chidi et al. [30] observed that the initial $\mathrm{pH} 6$ was the optimum $\mathrm{pH}$ medium to produce the maximum xylanase activity. Abdel-Naby and Kown [29] also reported that $A$. niger NRC 107 produced the maximum xylanase activity of $8.24 \mathrm{U} / \mathrm{mL}$ at $\mathrm{pH}$ medium 6 .

On the other hand, the alkaline $\mathrm{pH}$ medium was detected using soybean hulls, giving rise to $7.6250 \pm 0.0050$ at $96 \mathrm{~h}$, where it produced the lowest xylanase activity of $0.9948 \pm 0.0304 \mathrm{U} / \mathrm{mL}$.

The reason for poor xylanase production at higher alkaline $\mathrm{pH}$ medium was probably due to the proteolytic inactivation of xylanases in medium containing soybean hulls. As for other carbon sources, $\mathrm{pH}$ medium at the optimum xylanase activity was found to be $6.7900 \pm$ $0.0600,7.2700 \pm 0.0050,6.6100 \pm 0.1800,5.9500 \pm 0.0150,7.1350 \pm$ $0.0450,6.7900 \pm 0.0700$ and $5.9850 \pm 0.0150$ for sawdust, palm kernel cake, barley husks, rice bran, wheat bran, sugarcane bagasse and glucose, respectively.

On the other hand, the $\mathrm{pH}$ medium of wheat bran and sawdust in bioreactor are shown in Figure 10. A. brasiliensis produced the maximum xylanase activity using wheat bran at $\mathrm{pH} 5.7200 \pm 0.1100$. Likewise, the optimum medium $\mathrm{pH}$ for the maximum xylanase production using sawdust was $6.2050 \pm 0.1550$. Optimum $\mathrm{pH}$ medium from both carbon sources lied from the range of 5.8 to 6.8 .

Table 11 shows the optimum $\mathrm{pH}$ medium for the production of xylanase using wheat bran and sawdust in bioreactor.

In shake flask culture, the fungus produced the maximum xylanase activity of $1.1162 \pm 0.0034 \mathrm{U} / \mathrm{mL}$ at the optimum $\mathrm{pH}$ of $7.1350 \pm$ 0.0450 using wheat bran as carbon source. Meanwhile in bioreactor, using the same agro-residual waste, $A$. brasiliensis produced the relatively higher maximum xylanase activity of $3.1126 \pm 0.2462 \mathrm{U} / \mathrm{mL}$ at $\mathrm{pH} 5.7200 \pm 0.1100$.

Table 12 shows the $\mathrm{pH}$ medium for the production of xylanase from wheat bran as the optimised carbon source by $A$. brasiliensis in shake flask culture and bioreactor.

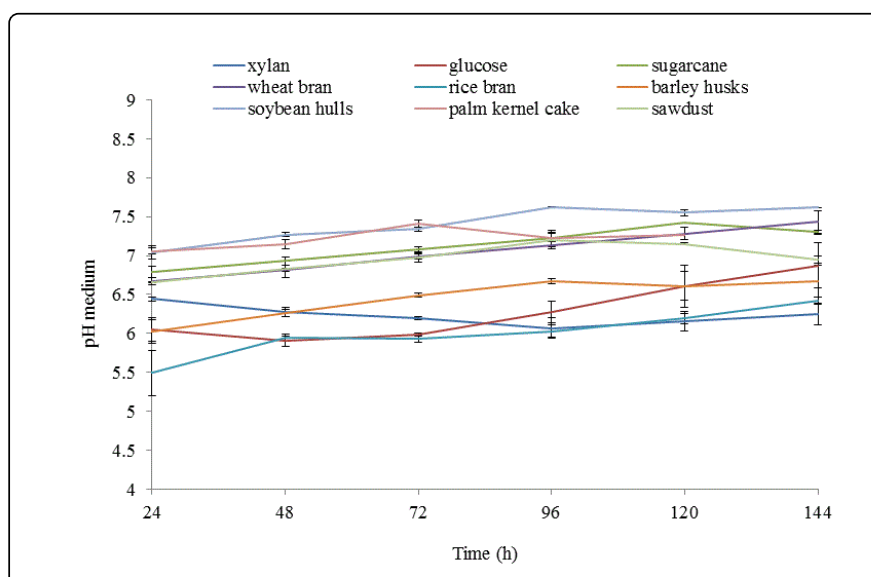

Figure 9: $\mathrm{pH}$ medium profile of Aspergillus brasiliensis using different agro-residual wastes compared to xylan and glucose as the sole carbon source in SmF of shake flask culture for $144 \mathrm{~h}$. Xylan and glucose were elucidated as control in this study, respectively. 
Citation: Ling Ho H, Phang JH (2015) Bioprocessing of Agro-Residual Wastes for Optimisation of Xylanase Production by Aspergillus brasiliensis in Shake Flask Culture and Its Scaling up Elucidation in Stirred Tank Bioreactor. J Biodivers Biopros Dev 2: 148. doi: $10.4172 / 2376-0214.1000148$

Page 12 of 14

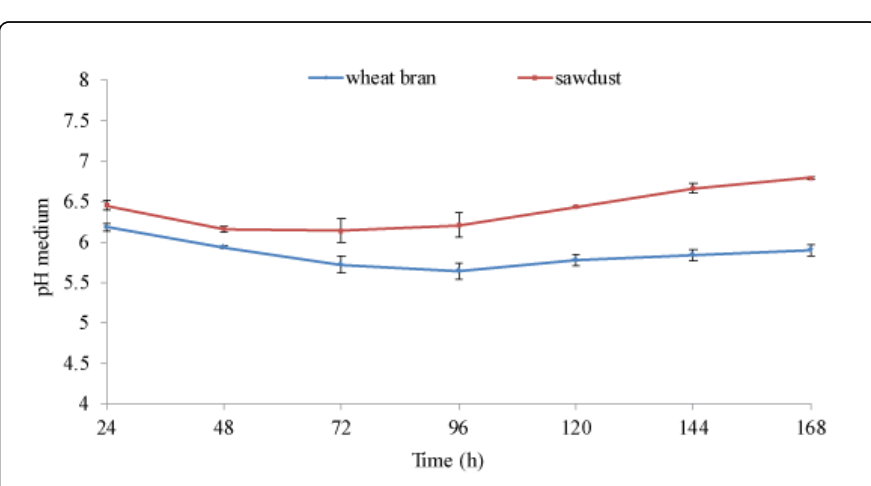

Figure 10: $\mathrm{pH}$ medium profile of Aspergillus brasiliensis using agro-residual wastes of wheat bran and sawdust as the carbon source in stirred tank bioreactor for $168 \mathrm{~h}$, respectively. Based on the result, using wheat bran as the optimised agro-residual waste, A. brasiliensis produced the maximum xylanase activity of $3.1126 \pm$ $0.2462 \mathrm{U} / \mathrm{mL}$ at $\mathrm{pH} 5.7200 \pm 0.1100$ in the bioreactor.

\begin{tabular}{|l|l|l|}
\hline Carbon source & Time $(\mathbf{h})$ & Optimum $\mathbf{~ p H}$ medium \\
\hline Xylan & 72 & $6.1900 \pm 0.0200$ \\
\hline Glucose & 72 & $5.9850 \pm 0.0150$ \\
\hline Sawdust & 72 & $6.7900 \pm 0.0600$ \\
\hline Wheat bran & 96 & $7.1350 \pm 0.0450$ \\
\hline Sugarcane bagasse & 48 & $6.7900 \pm 0.0700$ \\
\hline Rice bran & 48 & $5.9500 \pm 0.0150$ \\
\hline Barley husks & 120 & $6.6100 \pm 0.1800$ \\
\hline Palm kernel cake & 144 & $7.2700 \pm 0.0050$ \\
\hline Soybean hulls & 96 & $7.6250 \pm 0.0050$ \\
\hline
\end{tabular}

Table 10: Optimum $\mathrm{pH}$ medium for the production of xylanases from different carbon sources in shake flask culture.

\begin{tabular}{|l|l|l|}
\hline Agro-residual waste & Time $(\mathbf{h})$ & Optimum $\mathbf{p H}$ medium \\
\hline Wheat bran & 72 & $5.7200 \pm 0.1100$ \\
\hline Sawdust & 96 & $6.2050 \pm 0.1550$ \\
\hline
\end{tabular}

Table 11: Optimum $\mathrm{pH}$ medium for the production of xylanase from wheat bran and sawdust in bioreactor.

\begin{tabular}{|l|l|l|}
\hline Agro-residual waste & Time $(\mathbf{h})$ & Optimum $\mathbf{p H}$ medium \\
\hline Shake flask culture & 96 & $7.1350 \pm 0.0450$ \\
\hline Bioreactor & 72 & $5.7200 \pm 0.1100$ \\
\hline
\end{tabular}

Table 12: $\mathrm{pH}$ medium profile during the production of xylanase from wheat bran as the optimised carbon source by $A$. brasiliensis in shake flask culture and bioreactor.

\section{Conclusion}

SmF was carried out in the present study for the production of xylanase by $A$. brasiliensis using various agro-residual wastes including wheat bran, rice bran, sawdust, barley husks, soybean hulls, palm kernel cake and sugarcane bagasse with xylan and glucose as control. The approach of SmF offers several advantages such as providing uniform nutrient distribution to the microorganisms and better control rate of aeration and agitation. In shake flask culture, xylan was found to be the optimum carbon source for the production of xylanase with $11.2128 \pm 1.7030 \mathrm{U} / \mathrm{mL}$. Nonetheless, xylan is not economical for the industrial production of xylanase. Therefore, the agro-residual wastes such as sawdust and wheat bran which produced appreciable amount of xylanase with $1.2343 \pm 0.0809$ and $1.1162 \pm$ $0.0034 \mathrm{U} / \mathrm{mL}$ were further investigated in scale up fermentation. Large scale production using bioreactor in the current study was carried out to elucidate the xylanase activity using the optimised carbon sources that was determined from the small scale fermentation of shake flask culture. In the present study, wheat bran was found to produce higher xylanase activity of $3.1126 \pm 0.2462 \mathrm{U} / \mathrm{mL}$ in bioreactor.

Higher xylanase activity obtained from large scale fermentation was due to better aeration and agitation that could have favoured the growth of the microorganism as well as the production of xylanase. By comparing both wheat bran and sawdust in bioreactor, earlier served to be the better substrate for xylanase production. Xylanase activity observed in wheat bran was about 2-fold higher than sawdust. In addition, the fermentation period for wheat bran at $72 \mathrm{~h}$ was comparatively shorter than sawdust at $96 \mathrm{~h}$. The shorter fermentation period which equivalent to production period was pivotal since it could reduce the cost of xylanase production as well as minimise the risk of contamination during fermentation process in the industrial point of view. Conclusively, wheat bran and sawdust were able to produce appreciable amount of xylanase in small scale fermentation. Likewise, in the bioreactor study, wheat bran was tended to favour the production of xylanase when compared to the sawdust. Therefore, it holds great potential to become the cost effective carbon source for the production of xylanase in SmF.

The progress in biotechnology of xylanases is truly remarkable, as a result, it attracts worldwide attention in the recent years. Hence, continued research to meet the growing demand of xylanase and to realize their full potential in biotechnology is crucial. Several successful attempts have been carried out to improve the production of xylanase such as co-culturing of microorganisms [84], increase of substrate concentration [85] and pre-treat processes on the agro-residues [70]. Nonetheless, proper fermentation technique is by far the most important factor in order to produce enzymes commercially. Besides searching for attempts to improve production of xylanase, it is also important to look for other cheap carbon sources specifically with high xylan content. Moreover, screening for the new fungal strains to synthesize high levels of xylanase within the shortest fermentation period is significantly vital. In current study, $A$. brasiliensis was found to produce appreciable amount of xylanase. The work presented here has focused on the production of xylanase under optimised growth conditions. Therefore, in order to increase the level of xylanase production, further improvements are required to maximise the productivity yield in SmF. SmF via airlift tower loop bioreactor is a good alternative for higher production yield of xylanase [62]. In a nutshell, the result findings obtained in this study provide a fundamental frame work for the continuous study of xylanase production in shake flask culture and bioreactor system by $A$. 
Citation: Ling Ho H, Phang JH (2015) Bioprocessing of Agro-Residual Wastes for Optimisation of Xylanase Production by Aspergillus brasiliensis in Shake Flask Culture and Its Scaling up Elucidation in Stirred Tank Bioreactor. J Biodivers Biopros Dev 2: 148. doi: $10.4172 / 2376-0214.1000148$

Page 13 of 14

brasiliensis. In other words, this would be preliminary study on the use of agro-residual wastes for the large production of xylanase in batch fermentation in stirred tank bioreactor.

\section{References}

1. Howard RL, Abotsi E, Jansen van Rensburg EL, Howard S (2003) Lignocellulose biotechnology: Issues of bioconversion and enzyme production. African Journal of Biotechnology 2: 602-619.

2. Kim S, Dale B (2004) Global potential bioethanol production from wasted crops and crop residues. Biomass and Bioenergy 26: 361-375.

3. Abu EA, Onyenekwe PC, Ameh DA, Agbaji AS, Ado SA (2000) Cellulase production from sorghum bran by Aspergillus niger SL 1: An assessment of pretreatment methods. Proceedings of the International Conference on Biotechnology Commercialization and Food Security. 153-159.

4. Pang PK, Ibrahim CO (2004) Xylanase production by a local fungal isolate, Aspergillus niger USM11 via solid state fermentation using palm kernel cake (PKC) as substrate. Songklanakarin J Sci Technol 27: 326-336.

5. Lee CK, Darah I, Ibrahim CO (2011) Production and optimization of cellulase enzyme using Aspergillus niger USM AI 1 and comparison with Trichoderma reesei via solid state fermentation system. Research Biotechnological Research International 1-6.

6. Bajpai P1 (1997) Microbial xylanolytic enzyme system: properties and applications. Adv Appl Microbiol 43: 141-194.

7. Bhat MK1 (2000) Cellulases and related enzymes in biotechnology. Biotechnol Adv 18: 355-383.

8. Subramaniyan S, Prema P (2002) Biotechnology of microbial xylanases: enzymology, molecular biology, and application. Crit Rev Biotechnol 22: 33-64.

9. Liu C, Sun ZT, Du JH, Wang J (2008) Response surface optimization of fermentation conditions for producing xylanase by Aspergillus niger SL-05. Journal Industrial of Microbiology and Biotechnology 35: 703-711.

10. Polizeli ML, Rizzatti AC, Monti R, Terenzi HF, Jorge JA, et al. (2005) Xylanases from fungi: properties and industrial applications. Appl Microbiol Biotechnol 67: 577-591.

11. Twomey LN, Pluske JR, Rowe JB, Choct W, Pethick DW, et al. (2003) The effects of increasing levels of soluble non-starch polysaccharides and inclusion of feed enzymes in dog diets on faecal quality and digestibility. Animal Feed Science Technology 108: 71-82.

12. Christakopoulos P, Katapodis P, Kalogeris E, Kekos D, Macris BJ, et al (2003) Antimicrobial activity of acidic xylo-oligosaccharides produced by family 10 and 11 endoxylanases. Int J Biol Macromol 31: 171-175.

13. Arora N, Banerjee AK, Mutyala S, Murty US (2009) Comparative characterization of commercially important xylanase enzymes. Bioinformation 3: 446-453.

14. Pham PL, Taillandier P, Delmas M, Strehaiano P (1997) Optimization of a culture medium for xylanase production by Bacillus sp. using statistical experimental designs. World J Microbiol Biotechnol 14: 185-190.

15. Abdeshahian P, Samat N, Yusoff WM (2009) Xylanase production by Aspergillus niger FTCC 5003 using palm kernel cake in fermentative bioprocess. Pak J Biol Sci 12: 1049-1055.

16. Gaanappriya M, Guhankumar P, Balakrishnan V (2011) Isolation of xylan degrading enzyme from Trichoderma spp. Research in Plant Biology 1: 15-20.

17. Ibrahim CO1 (2008) Development of applications of industrial enzymes from Malaysian indigenous microbial sources. Bioresour Technol 99: 4572-4582.

18. Laxman RS, Sonawane AP, More SV, Rao BS, Rele MV, et al. (2005) Optimization and scale up of production of alkaline protease from Conidiobolus coronatus. Process Biochemistry 40: 3152-3158.

19. Hong LS, Ibrahim D, Omar IC (2011) Lignocellulolytic materials-as a raw material for the production of fermentable sugars via solid state fermentation. Asian Journal of Scientific Research 4: 53-61.
20. Bailey MJ, Biely P, Poutanen K (1992) Laboratory testing of methods for assay of xylanase activity. J Biotechnol 23: 257-270.

21. Lowry OH, Rosebrough NI, Farr Al, Randall RI (1951) Protein measurement with the Folin phenol reagent. J Biol Chem 193: 265-275.

22. Wu M, Li SC, Yao JM, Pan RR, Yu ZL (2005) Mutant of a xylanaseproducing strain of Aspergillus niger in solid state fermentation by low energy ion implantation. World Journal Microbiology Biotechnology 21: 1045-1049.

23. Xu YX, Li YL, Xu SC, Liu L, Wang X, et al.(2008) Improvement of xylanase production by Aspergillus niger XY-1 using response surface methodology for optimizing the medium composition. Journal Zhejiang University Science Biology 9: 558-566.

24. Kar S, Mandal A, Mohapatra PK, Mondal KC, Pati BR (2006) Production of cellulase-free xylanase by Trichoderma reesei SAF3. Brazilian Journal Microbiology 37: 462-464.

25. Cai Q, Yue T, Cheng J, Ma Q (2003) The screening of culture condition and properties of xylanase by white rot fungus Pleorotus ostreatus. Process Biochemistry 25: 2-6.

26. Balakrishnan H, Srinivasan MC, Rele MV (1997) Extracellular protease activities in relation to xylanase secretion in an alkalophilic Bacillus spp. Biotechnology 18: 599-601.

27. Kadowaki MK, Pacheco MAC, Peralta RM (1995) Xylanase production by Aspergillus isolates grown on corn cob. Journal Microbiology 263: 219-223.

28. Damaso MC, Andrade CM, Pereira Júnior N (2000) Use of corncob for endoxylanase production by thermophilic fungus Thermomyces lanuginosus IOC-4145. Appl Biochem Biotechnol 84-86: 821-34.

29. Abdel-Naby MA, Kown DY (1992) Production of xylanase and Bxylosidase by Aspergillus niger NRC 107. Korean Journal of Applied Microbiology and Biotechnology 20: 543-550.

30. Chidi SB, Godana B, Ncube I, Rensburg EJV, Cronshaw A, et al.(2008) Production, purification and characterization of cellulase-free xylanase from Aspergillus terreus UL 4209. African Journal of Biotechnology 7: 3939-3948.

31. Puls J (1997) Chemistry and biochemistry of hemicelluloses: Relationship between hemicellulose structure and enzymes required for hydrolysis. Macromolecule Symphosium 120: 183-196.

32. Kulkarni N, Shendye A, Rao M (1999) Molecular and biotechnological aspects of xylanases. FEMS Microbiol Rev 23: 411-456.

33. Thomson JA1 (1993) Molecular biology of xylan degradation. FEMS Microbiol Rev 10: 65-82.

34. Pang PK, Omar IC (2005) Xylanase production by a local fungal isolate, Aspergillus niger USM AI 1 via solid state fermentation using palm kernel cake (PKC) as substrate. Journal Science Technology 27: 325-336.

35. Okafor UA, Okochi VI, Onyegeme-okerenta BM, Nwodo-Chinedu S (2007) Xylanase production by Aspergillus niger ANL 301 using agrowastes. African Journal of Biotechnology 6: 1710-1714.

36. Ronne H1 (1995) Glucose repression in fungi. Trends Genet 11: 12-17.

37. Kuhad RC, Manchanda M, Singh A (1998) Optimization of xylanase production by a hyper xylanolytic mutant strain of Fusarium oxysporum. Process Biochemistry 33: 641-647.

38. Collins T, Gerday C, Feller G (2005) Xylanases, xylanase families and extremophilic xylanases. FEMS Microbiol Rev 29: 3-23.

39. Pandey A, Selvakumar P, Soceal CR, Nigam P (1999) Solid state fermentation for the production of Industrial enzymes. Current Science 77: 149-162.

40. Techapun C, Poosaran N, Watanabe M, Sasaki K (2003) Thermostable and alkaline-tolerant microbial cellulase-free xylanases produced from agricultural wastes and the properties required for use in pulp bleaching bioprocesses: A review. Process Biochemistry 38: 1327-1340.

41. Bakri Y, Jacques P, Thonart P (2003) Xylanase production by Penicillium canescens 10-10c in solid-state fermentation. Appl Biochem Biotechnol 105 -108: 737-48. 
Citation: Ling Ho H, Phang JH (2015) Bioprocessing of Agro-Residual Wastes for Optimisation of Xylanase Production by Aspergillus brasiliensis in Shake Flask Culture and Its Scaling up Elucidation in Stirred Tank Bioreactor. J Biodivers Biopros Dev 2: 148. doi: $10.4172 / 2376-0214.1000148$

Page 14 of 14

42. Poorna CA, Prema P (2006) Production and partial characterization of endoxylanase by Bacillus pumilus using agro industrial residues. Biochem Eng J 32: 106-112.

43. Silva RD, Lago ES, Merheb CW, Macchione MM, Park YK, et al. (2005) Production of xylanase and cmcase on solid state fermentation in different residues by Thermoascus auranticus Miehe. Brazilian Journal of Microbiology 36: 235-241.

44. Siedenberg D, Gerlach SR, Weigel B, Schugerl K, Giuseppin MLF, et al. (1997) Production of xylanase by Aspergillus awamori on synthetic medium in stirred tank and airlift tower loop reactors: the influence of stirrer speed and phosphate concentration. Journal of Biotechnology 56: 103-114.

45. Palmarola-Adrados B, Choteborská P, Galbe M, Zacchi G (2005) Ethanol production from non-starch carbohydrates of wheat bran. Bioresour Technol 96: 843-850.

46. Muthezilan R, Ashok R, Jayalakshmi S (2007) Production and optimization of thermostable alkaline xylanase by Penicillium oxalicum in solid state fermentation. African Journal of Microbiology Research 1: 20-28.

47. Pal A, Khanum F (2011) Enhanced xylanase production from Aspergillus flavus. Food Technology Biotechnology 49(2): 228-236.

48. Ellouze O, Fattouch S, Mestiri F, Radhouen M, Marzouki MN (2008) Optimization of extracellular xylanase production by Sclerotinia sclerotiorum S2 using factorial design. Indian Journal of Biochemistry and Biophysics 45: 404-409.

49. Ong LGA, Abd-Aziz S, Noraini S, Karim MIA, Hassan HA (2004) Enzyme production and profile by Aspergillus niger during solid substrate fermentation using palm kernel cake as substrate. Applied Biochemical Biotechnology 118: 73-79.

50. Brijwani K, Oberoi HS, Vadlani PV (2010) Production of cellulolytic enzyme system in mixed culture solid-state fermentation of soybean hulls supplemented with wheat bran. Process Biochemistry 45: 120-128.

51. Kim JD1 (2005) Production of Xylanolytic Enzyme Complex from Aspergillus flavus using Agricultural Wastes. Mycobiology 33: 84-89.

52. Gupta VK, Gaur N, Kumar P, Yadav IJ, Darmwal NS (2009) Optimization of xylanase production from Fusarium solani F7. American Journal of Food Technology 4: 20-29.

53. Pandey A, Socool CR, Nigam P, Soccol VT (2000) Biotechnological Potential of agroindustrial residues 1: Sugarcane bagasse. Bioresource Technology 74: 69-80.

54. De-Paula EH, Ramos LP, Azevedo MD (1999) The Potential of Humicolagrisea var. thermoidea for bioconversion of sugarcane bagasse. Bioresource Technology 68: 35-41.

55. Ghoshal G, Banerkee UC, Chisti Y, Shivhare US (2012) Optimization of xylanase production from Penicillium citrinum in solid-state fermentation. Chemical Biochemistry Engineering 26: 61-69.

56. Gawande PV, Kamat MY (1999) Production of Aspergillus xylanase by lignocellulosic waste fermentation and its application. J Appl Microbiol 87: 511-519.

57. Soliman HM, Sherief AA, El-Tanash AB (2012) Production of xylanase by Aspergillus niger and Trichorderma viride using some agriculture residues. International Journal of Agricultural Research 7: 46-57.

58. Bakri Y, Mekaeel A, Koreith A (2011) Influence of agitation speeds and aeration rates on the xylanase activity of Aspergillus niger SS7. Brazilian Archives Biology and Technology 54: 659-664.

59. Velmurugan R, Divya S (2011) Xylanase production by Aspergillus niger fermented in wheat bran and rice straw. Electronic Journal of Pharmacology and Therapy 4: 21-23.

60. Li Y, Cui FJ, Liu ZQ, Xu YY, Zhao H (2007) Improvement of xylanase production by Penicillium oxalicum $\mathrm{ZH}-30$ using response surface methodology. Enzyme and Microbial Technology 40: 1381-1388.

61. Bailey MJ, Poutanen K (1989) Production of xylanolytic enzymes by strains of Aspergillus. Applied Microbiology and Biotechnology 30: 5-10.

62. Michelin M, Polizeli MTM, Silva DP, Ruzene DS, Vicente A, et al. (2011) Production of xylanolytic enzymes by Aspergillus terricola in stirred tank and airlift tower loop bioreactors. Journal Industrial of Microbiology and Biotechnology 38: 1979-1984.

63. Slavin J1 (2003) Why whole grains are protective: biological mechanisms. Proc Nutr Soc 62: 129-134.

64. Pandey A (1992) Recent process developments in solid-state fermentation. Process Biochemistry 27: 109-117.

65. Javed MR, Rashid MH, Mukhtar Z, Riaz M, Nadeem H, et al. (2011) Kinetics and thermodynamics of high level $B$-glucosidase production by mutant derivative of Aspergillus niger under submerged growth conditions. African Journal Microbiology 5: 2528-2538.

66. Sindhu R, Suprabha GN, Shashidhar S (2009) Optimization of process parameters for the production of alpha amylase from Penicillium janthinellum (NCIM 4960) under solid state fermentation. African Journal Microbiology Resolution 3: 498-503.

67. Gessesse A, Mamo G (1999) High-level xylanase production by an alkaliphilic Bacillus sp. by using solid-state fermentation. Enzyme Microbiology and Technology 25: 68-72.

68. Alvarez P, Blanco C, Santamaria R, Grand M (2005) Lignocellulose/pitch based composites. Composites Part A 36: 649-657.

69. Batzias FA, Sidiras DK (2007) Simulation of dye adsorption by beech sawdust as affected by $\mathrm{pH}$. J Hazard Mater 141: 668-679.

70. Dashtban M, Schraft H, Qin W (2009) Fungal bioconversion of lignocellulosic residues; opportunities \& perspectives. Int J Biol Sci 5: 578-595.

71. Hahn-Hägerdal B, Galbe M, Gorwa-Grauslund MF, Lidén G, Zacchi G (2006) Bio-ethanol--the fuel of tomorrow from the residues of today. Trends Biotechnol 24: 549-556.

72. Ritschkoff AC, Buchert J, Viikari L (1994) Purification and characterization of a thermophilic xylanase from the brown rot fungus Gloeophyllum trabeum. Journal of Biotechnology 32: 67-74.

73. Paice MG, Jurasek L, Carpenter MR, Smillie LB (1978) Production, characterization, and partial amino acid sequence of xylanase A from Schizophyllum commune. Appl Environ Microbiol 36: 802-808.

74. Cowan MM1 (1999) Plant products as antimicrobial agents. Clin Microbiol Rev 12: 564-582.

75. Sumthong P (2007) Antimicrobial compounds as side products from the agricultural processing industry. Doctorial thesis. The Netherlands: Leiden University.

76. Scalbert A (1991) Antimicrobial properties of tannins. Phytochemistry 30: 3875-3883.

77. Batzias FA, Sidiras DK (2007) Simulation of dye adsorption by beech sawdust as affected by pH. J Hazard Mater 141: 668-679.

78. Ciocan ID, Bara II (2007) Plant products as antimicrobial agents. Scientific Genetics and Biology Molecular 151-156.

79. Khan Y, Dahot U, Khan Y (1992) Single cell protein production by Penicillum javanicum from pretreated rice husk. J Islam Acad Sci 5: 39-43.

80. Oshoma CE, Ikenebomeh MJ (2005) Production of Aspergillus niger biomass from rice bran. Pakistan Journal of Nutrition 4: 32-36.

81. Chinedu N, Nwinyi S, Obinna C, Okochi VI (2008) Growth and cellulase activity of wild type Aspergillus niger ANL 301 in different carbon sources. Canadian Journal of Pure and Applied Sciences 2: 357-362.

82. Kang SW, Park YS, Lee JS, Hong SI, Kim SW (2004) Production of cellulases and hemicellulases by Aspergillus niger KK2 from lignocellulosic biomass. Bioresour Technol 91: 153-156.

83. De Vries RP, Visser J (2001) Aspergillus enzymes involved in degradation of plant cell wall polysaccharides. Microbiol Mol Biol Rev 65: 497-522.

84. Juhasz T (2005) Enzymes for improved hydrolysis of lignocellulosics. Thesis: Budapest University of Technology and Economics.

85. Ahmad Z, Butt MS, Anjum FM, Awan MS, Rathore HA, et al. (2012) Effect of corn cobs concentration on xylanase biosynthesis by Aspergillus niger. African Journal of Biotechnology 11: 1674-1682. 